\title{
Can Propolis Be a Useful Adjuvant in Brain and Neurological Disorders and Injuries? A Systematic Scoping Review of the Latest Experimental Evidence
}

\author{
Felix Zulhendri ${ }^{1, *} \mathbb{\infty}$, Conrad O. Perera ${ }^{2}\left(\mathbb{D}\right.$ and Steven Tandean ${ }^{3, *}$ \\ 1 Kebun Efi, Kabanjahe 22171, North Sumatra, Indonesia \\ 2 Food Science Program, School of Chemical Sciences, University of Auckland, 23 Symonds Street, Auckland \\ CBD, Auckland 1010, New Zealand; c.perera@auckland.ac.nz \\ 3 Department of Neurosurgery, Faculty of Medicine, Universitas Sumatera Utara, \\ Medan 20222, Sumatera Utara, Indonesia \\ * Correspondence: felix.zulhendri@gmail.com (F.Z.); steven.tandean@usu.ac.id (S.T.)
}

Citation: Zulhendri, F.; Perera, C.O.; Tandean, S. Can Propolis Be a Useful Adjuvant in Brain and Neurological Disorders and Injuries? A Systematic Scoping Review of the Latest Experimental Evidence. Biomedicines 2021, 9, 1227. https://doi.org/ 10.3390/biomedicines 9091227

Academic Editor: Wen-Chi Hou

Received: 19 August 2021

Accepted: 14 September 2021

Published: 15 September 2021

Publisher's Note: MDPI stays neutral with regard to jurisdictional claims in published maps and institutional affiliations.

Copyright: (c) 2021 by the authors. Licensee MDPI, Basel, Switzerland. This article is an open access article distributed under the terms and conditions of the Creative Commons Attribution (CC BY) license (https:// creativecommons.org/licenses/by/ $4.0 /)$.

\begin{abstract}
Propolis has been used therapeutically for centuries. In recent years, research has demonstrated its efficacy as a potential raw material for pharmaceuticals and nutraceuticals. The aim of the present scoping review is to examine the latest experimental evidence regarding the potential use of propolis in protecting the brain and treating neurological disorders and injuries. A systematic scoping review methodology was implemented. Identification of the research themes and knowledge gap was performed. After applying the exclusion criteria, a total of 66 research publications were identified and retrieved from Scopus, Web of Science, Pubmed, and Google Scholar. Several key themes where propolis is potentially useful were subsequently identified, namely detoxification, neuroinflammation, ischemia/ischemia-reperfusion injury/traumatic brain injury, Alzheimer's disease, Parkinson's disease, and epilepsy models, depression, cytotoxicity, cognitive improvement, regenerative medicine, brain infection, and adverse effects. In conclusion, propolis is shown to have protective and therapeutic benefits in alleviating symptoms of brain and neurological disorders and injuries, demonstrated by various in vitro studies, animal models, and human clinical trials. Further clinical research into this area is needed.
\end{abstract}

Keywords: adjuvant therapy; brain; neurology; nutraceuticals; pharmaceuticals; propolis

\section{Introduction}

Propolis is a natural, non-toxic, and resinous substance collected by bees to maintain hive homeostasis and to provide physical and biochemical protection to the hive [1-3]. Propolis has been used therapeutically for centuries as it possesses various biological activities including antimicrobial, anti-inflammatory, anti-cancer, and antioxidant properties [4-6]. Several preliminary clinical studies have also demonstrated the efficacy of propolis as an adjuvant for treating Sars Cov-2 infections [7,8]. Therefore, propolis appears to be a promising raw material for the future development of new therapeutic compounds. The biological activities and therapeutic properties of propolis are shown to be due to its content of plant secondary metabolite compounds such as phenolics and terpenoids [9].

Another exciting area of research is the use of propolis in treating neurological and brain disorders. However, the efficacy of propolis in this particular area has not been thoroughly explored. The main objectives of the present scoping review are to investigate the landscape of propolis research, identify the knowledge and research gap, and provide guidance for future research investigating the potential therapeutic uses of propolis in treating brain and neurological injuries, either as pharmaceuticals or nutraceuticals. 


\section{Methods}

The scoping review was performed in accordance to the guidelines provided by Peters et al. and Munn et al. [10,11]. The four-phase flow diagram of the Preferred Reporting Items for Systematic Reviews and Meta-Analyses (PRISMA) was followed [12].

\subsection{Search Strategy and Study Selection}

The guiding question for the present scoping review was as follows: Can propolis be used as adjuvant therapy and /or to protect brain and treat neurological disorders? Two independent reviewers (F.Z. and S.T.) performed the searches up to 5 August 2021. The databases searched were Scopus, Pubmed, Web of Science, and Google Scholar. Table S1 illustrates the search strategy and the terms included in the search. Limited keyword searches were used for Google Scholar as expansive keyword searches appeared to be redundant.

The objective of the present scoping review is to evaluate the latest experimental evidence in the potential use of propolis, and therefore the search was limited to the last ten years of research: 2012-2021. In addition, we also focus on the studies that evaluate propolis as a whole and not the individual bioactive components of propolis. Consequently, we did not use the terms that describe individual bioactive components of propolis such as caffeic acid phenethyl ester (CAPE), pinocembrin, apigenin, and so on. However, during the search process, if the articles that described the individual bioactive components of propolis appeared, we would include them in the screening process. Moreover, we excluded studies that use synthetic derivatives of propolis bioactive compounds.

\subsection{Eligibility Criteria}

Any article that describes the potential use of propolis in protecting the brain or treating neurological disorders was selected including in vitro studies, animal models, and human clinical trials. We included all articles from all fields of science and technology. The titles and abstracts were analyzed and selected according to the eligibility criteria. Review studies were excluded as they might impart biases to the present study. Only articles that were written in English were included.

\subsection{Data Collection}

Two reviewers (F.Z. and S.T.) assessed the search results independently. If any disagreement arose on the eligibility criteria of a particular article, the disagreement was resolved through discussion and consensus. The studies that were both included and excluded were recorded in Mendeley. The duplicates were then removed. The collected articles were then screened by analyzing the titles, keywords, and abstracts. The articles that did not fit in the guiding question were subsequently removed. For the remaining articles, further screening was performed by analyzing the full texts. For articles where we could not find the full text, we analyzed the abstracts and subsequently included the articles if the abstracts clearly stated the experimental methods, analyses, and detailed results.

The following data of the resulting articles were then collected and tabulated in Microsoft Excel; full reference, types of study, types of propolis extract and/or propolis bioactive compounds, geographic locations of the propolis source, and measured outcome. The reviewers subsequently analyzed the titles, abstracts, and full texts and categorized the included studies into the appropriate themes.

\section{Results}

The initial search resulted in 3624 scientific articles. Duplicates of 2683 were subsequently removed. Further screening based on the titles and abstracts excluded 799 articles. The full texts of the 142 articles were then analyzed and screened. The final screening resulted in 66 articles. Figure 1 illustrates the screening process. 


\section{Identification of studies via databases and registers}

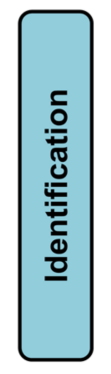

Records identified from*:

Scopus $(n=979)$

Web of Science $(n=855)$

Pubmed $(n=410)$

Google Scholar $(n=1380)$
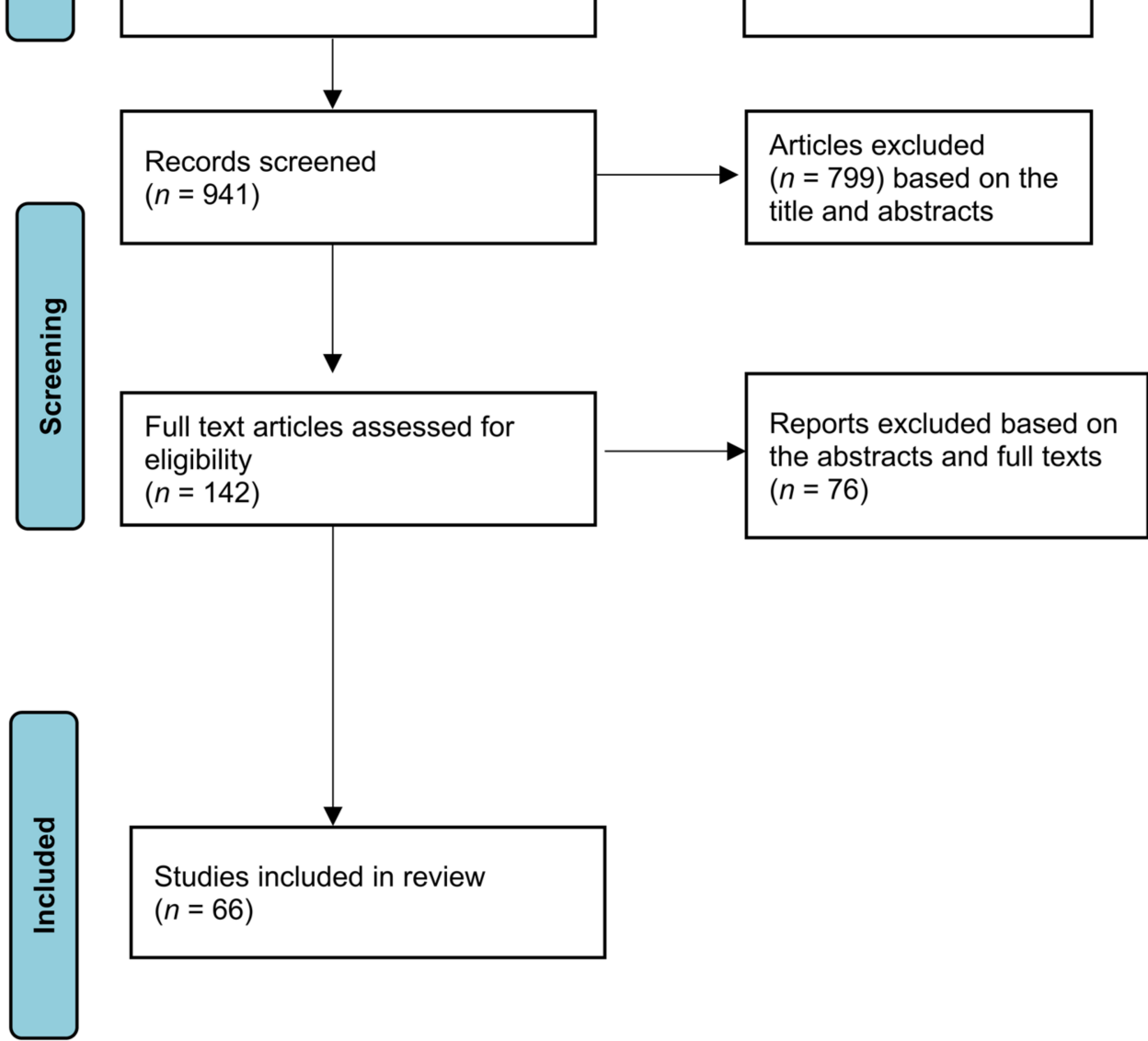

Figure 1. The screening process of the studies adapted from Preferred Reporting Items for Systematic reviews and Meta-Analyses (PRISMA).

The qualitative analysis of the 66 included articles was performed and the articles were categorized into several themes. Table 1 illustrates the themes represented in the included studies; brain infection (2\%), ischemia/ischemia-reperfusion/traumatic brain injuries / aneurysm (14\%), detoxification (24\%), Alzheimer's disease model (9\%), Parkinson's disease model $(8 \%)$, epilepsy model $(3 \%)$, cognitive improvement $(6 \%)$, regenerative medicine (3\%), neuroinflammation/pain/oxidative stress $(12 \%)$, depression \& stress models $(9 \%)$, cytotoxicity $(8 \%)$, adverse effects $(2 \%)$, and others $(2 \%)$. Table 2 summarizes the themes, references, and the main findings alongside the types of propolis extracts and bioactive compounds used in the included studies. In addition, Figure 2 illustrates the types of studies in the included articles, namely animal models (67\%), cell cultures (22\%), in vitro $(6 \%)$, randomized placebo-controlled human clinical trials $(4 \%)$, and case reports $(1 \%)$. The percentages are rounded to the nearest whole number. 
Table 1. The key themes of the included studies.

\begin{tabular}{cc}
\hline Themes & Percentage (\%) \\
\hline Adverse effects & 2 \\
\hline Alzheimer's disease model & 9 \\
\hline Brain infection & 2 \\
\hline Cognitive Improvement & 6 \\
\hline Cytotoxicity & 8 \\
\hline Depression and Stress models & 9 \\
\hline Detoxification & 24 \\
\hline Epilepsy model & 3 \\
\hline Ischemia/Ischemia-Reperfusion injury/Traumatic & 14 \\
\hline Brain Injury/Aneurysm & 12 \\
\hline Neuroinflammation, Pain, and Oxidative stress & 8 \\
\hline Parkinson's disease model & 3 \\
\hline Regenerative medicine & 2 \\
\hline Others &
\end{tabular}

Table 2. The summary of the included studies in the present scoping review.

\begin{tabular}{|c|c|c|c|c|c|}
\hline Themes & References & $\begin{array}{l}\text { Types of } \\
\text { Study }\end{array}$ & $\begin{array}{l}\text { Types of Propolis } \\
\text { Extracts and/or } \\
\text { Propolis Bioactive } \\
\text { Compounds }\end{array}$ & $\begin{array}{l}\text { Geographic } \\
\text { Locations of } \\
\text { the Propolis } \\
\text { Source }\end{array}$ & Measured Outcome \\
\hline Brain Infection & [13] & $\begin{array}{l}\text { Animal } \\
\text { model } \\
(n=140, \text { rats })\end{array}$ & $\begin{array}{l}\text { Hydroethanolic } \\
\text { extract } \\
0.1 \mathrm{~mL} \text { of } 1: 10 \mathrm{w} / \mathrm{v} \\
(25 \mathrm{~g} \text { in } 250 \mathrm{~mL})\end{array}$ & Egypt & $\begin{array}{l}\text { Propolis enhanced the } \\
\text { anti-Toxoplasma gondii activity of } \\
\text { Spiramycin }\end{array}$ \\
\hline \multirow{3}{*}{$\begin{array}{l}\text { Ischemia/Ischaemia- } \\
\text { Reperfusion injury/ } \\
\text { Traumatic Brain } \\
\text { Injury/Aneurysm }\end{array}$} & [14] & $\begin{array}{l}\text { Animal } \\
\text { model } \\
(n=12, \\
\text { rabbit })\end{array}$ & $\begin{array}{l}\text { Ethanolic extract } \\
100 \mathrm{mg} / \mathrm{kg} \mathrm{BW}\end{array}$ & Turkey & $\begin{array}{l}\text { Neuroprotective properties of } \\
\text { propolis demonstrated in the } \\
\text { post-operative Tarlov scores, } \\
\text { biochemical parameters such as } \\
\text { interleukin- } 6 \text { (IL-6), tumor } \\
\text { necrosis factor (TNF)- } \alpha \text {, } \\
\text { myeloperoxidase activity, } \\
\text { ischemia-modified albumin } \\
\text { (IMA), intercellular } \\
\text { adhesion molecule-1 (ICAM-1), } \\
\text { total oxidant status, and } \\
\text { histopathological examination. }\end{array}$ \\
\hline & [15] & $\begin{array}{l}\text { Animal } \\
\text { model } \\
(n=72, \text { mice })\end{array}$ & $\begin{array}{l}\text { Aqueous extract } \\
30,100 \text { and } \\
200 \mathrm{mg} / \mathrm{kg} \mathrm{BW}\end{array}$ & Iran & $\begin{array}{l}\text { Propolis improved grasping } \\
\text { ability and sensory-motor } \\
\text { function following permanent } \\
\text { middle cerebral artery } \\
\text { occlusion. }\end{array}$ \\
\hline & [16] & $\begin{array}{l}\text { Animal } \\
\text { model (rats, } \\
n=33 \text { ) }\end{array}$ & $\begin{array}{l}\text { Hydroethanolic } \\
\text { extract } \\
200 \mathrm{mg} / \mathrm{kg} \mathrm{BW}\end{array}$ & Indonesia & $\begin{array}{l}\text { Propolis induced the expression } \\
\text { of the protective heat-shock } \\
\text { protein (hsp)-70 and reduced } \\
\text { the expression of inflammatory } \\
\text { markers such as caspase- } 3 \text { and } \\
\text { apoptosis inducing factor in } \\
\text { traumatic brain injury animal } \\
\text { model. }\end{array}$ \\
\hline
\end{tabular}


Table 2. Cont.

\begin{tabular}{|c|c|c|c|c|}
\hline Themes & References & $\begin{array}{c}\text { Types of } \\
\text { Study }\end{array}$ & $\begin{array}{l}\text { Types of Propolis } \\
\text { Extracts and/or } \\
\text { Propolis Bioactive } \\
\text { Compounds }\end{array}$ & $\begin{array}{c}\text { Geographic } \\
\text { Locations of } \\
\text { the Propolis } \\
\text { Source }\end{array}$ \\
\hline
\end{tabular}

CAPE reduced the severity of elastase-induced aortic aneurysm by reducing the expression of

$\begin{array}{lll} & \text { Animal } & \text { Caffeic acid } \\ \text { model (rats, } & \text { phenethyl ester } \\ n=36) & \text { (CAPE) } \\ & 10 \mu \mathrm{mol}\end{array}$

Not specified

metalloproteinases MMP-2 and MMP-9, monocyte chemotactic protein-1 (MCP-1), and inducible nitric oxide synthase (iNOS). CAPE also circumvented the loss of vascular smooth muscle cells (VSMCs) in aortic walls of treated rats.

In cerebral ischemia-induced mice, propolis reduced the expression of malondialdehyde (MDA) and improved the

Animal Aqueous extract

[18] model (mice, 100 and $200 \mathrm{mg} / \mathrm{kg}$ Iran $n=72) \quad$ BW antioxidant status (ratio of superoxide dismutase (SOD) to glutathione peroxidase GPx). Propolis also ameliorated the sensory-motor impairment and neurological deficits induced by cerebral ischemia.

Propolis reduced the extent of neuronal damage in oxygen-glucose deprivation/reoxygenation (OGD/R)- induced cells.

Chrysin improved glutathione (GSH) level and decreased thiobarbituric acid reactive substances (TBARS) level.

[20] $\begin{array}{lll}\text { Animal } & \text { Chrysin } & \text { Not specified } \\ \text { model (mice, } & 50 \mathrm{mg} / \mathrm{kg} \mathrm{BW} & \end{array}$

Chrysin attenuated the development of neurodegenerative histopathologies associated with global cerebral ischemia/reperfusion in mice.

In sciatic nerve-injured rats, propolis improved the motor function and sciatic functional

Animal Hydroethanolic

[21] model (rats, extract1 and $n=36) \quad 10 \mathrm{mg} / \mathrm{kg} \mathrm{BW}$
Brazil index. Propolis also significantly accelerated the motor recovery and increased the number of myelinated fibers.

Propolis improved motor function (walking track and electrophysiological analyses), following crush injury of the sciatic nerve in rats. 
Table 2. Cont.

\begin{tabular}{|c|c|c|c|c|c|}
\hline Themes & References & $\begin{array}{l}\text { Types of } \\
\text { Study }\end{array}$ & $\begin{array}{l}\text { Types of Propolis } \\
\text { Extracts and/or } \\
\text { Propolis Bioactive } \\
\text { Compounds }\end{array}$ & $\begin{array}{l}\text { Geographic } \\
\text { Locations of } \\
\text { the Propolis } \\
\text { Source }\end{array}$ & Measured Outcome \\
\hline \multirow{7}{*}{ Detoxification } & [23] & $\begin{array}{l}\text { Cell cultures } \\
\text { (SH-SY5Y) }\end{array}$ & $\begin{array}{l}\text { Pinocembrin } \\
1-25 \mu \mathrm{M}\end{array}$ & Not specified & $\begin{array}{l}\text { Pinocembrin prevented the } \\
\text { Chlorpyrifos-induced } \\
\text { mitochondrial membrane } \\
\text { potential (MMP) loss and ATP } \\
\text { synthesis inhibition in SH-SY5Y } \\
\text { cells. Pinocembrin also induced } \\
\text { the anti-inflammatory activity. }\end{array}$ \\
\hline & [24] & $\begin{array}{l}\text { Cell cultures } \\
\text { (SH-SY5Y) }\end{array}$ & $\begin{array}{l}\text { Caffeic acid, } \\
\text { chrysin, quercetin } \\
\text { and ferulic acid } \\
100,200 \text { and } \\
400 \mu \mathrm{M}\end{array}$ & Not specified & $\begin{array}{l}\text { The phenolic compounds } \\
\text { inhibited the } \\
\text { cyclophosphamide-induced } \\
\text { apoptosis of SH-SY5Y cells. }\end{array}$ \\
\hline & [25] & $\begin{array}{l}\text { Cell cultures } \\
\text { (SH-SY5Y) }\end{array}$ & $\begin{array}{l}\text { Chrysin } \\
0.05 \mathrm{mM}\end{array}$ & Not specified & $\begin{array}{l}\text { Chrysin inhibited the } \\
\text { diclofenac-induced apoptosis of } \\
\text { SH-SY5Y cells. Chrysin } \\
\text { inhibited the expression of Bax, } \\
\text { cytochrome c, cas-3, cas- } 8 \text { and } p 53 \\
\text { genes associated with } \\
\text { diclofenac treatment. }\end{array}$ \\
\hline & [26] & $\begin{array}{l}\text { Animal } \\
\text { model (rats, } \\
n=40)\end{array}$ & $\begin{array}{l}\text { Hydroethanolic } \\
\text { extract } \\
200 \mathrm{~mL} / \mathrm{kg} \mathrm{BW}\end{array}$ & Egypt & $\begin{array}{l}\text { Propolis reduced the } \\
\text { development of aluminum } \\
\text { silicate-induced irregular } \\
\text { euchromatic nucleus and } \\
\text { significantly increased the } \\
\text { invagination of the nuclear } \\
\text { envelope of Purkinje cells in the } \\
\text { cerebellar cortex of aluminum } \\
\text { silicate-intoxicated rats. }\end{array}$ \\
\hline & [27] & $\begin{array}{l}\text { Animal } \\
\text { model (rats, } \\
n=24-32)\end{array}$ & $\begin{array}{l}\text { Not specified } \\
600 \mathrm{mg} / \mathrm{kg} \mathrm{BW}\end{array}$ & Not specified & $\begin{array}{l}\text { Propolis reduced the expression } \\
\text { of inflammatory markers; } \\
\text { malondealdehyde (MDA) and } \\
\text { nitric oxide (NO). Propolis } \\
\text { improved the antioxidant status } \\
\text { by maintaining glutathione } \\
\text { level and the activity of } \\
\text { superoxide dismutase and } \\
\text { catalase in monosodium } \\
\text { glutamate-intoxicated rats. } \\
\text { Propolis also prevented the } \\
\text { accumulation of } \beta \text {-amyloid and } \\
\text { oxidative-stress marker } \\
\text { 8-hydroxy-2'-deoxyguanosine. }\end{array}$ \\
\hline & [28] & $\begin{array}{l}\text { Animal } \\
\text { model (rats, } \\
n=24)\end{array}$ & $\begin{array}{l}\text { Propolis capsules } \\
\text { (extract not } \\
\text { specified) } \\
50 \mathrm{mg} / \mathrm{kg} \mathrm{BW}\end{array}$ & Not specified & $\begin{array}{l}\text { Propolis attenuated the } \\
\text { Paclitaxel-induced } \\
\text { morphological deterioration of } \\
\text { myelinated fibers of sciatic } \\
\text { nerve. }\end{array}$ \\
\hline & [29] & $\begin{array}{l}\text { Animal } \\
\text { model (rats, } \\
n=60)\end{array}$ & $\begin{array}{l}\text { Not specified } \\
100 \text { and } 200 \mathrm{mg} / \mathrm{kg}\end{array}$ & Not specified & $\begin{array}{l}\text { Propolis reduced the expression } \\
\text { of inducible nitric oxide } \\
\text { synthase (iNOS) gene in } \\
\text { thioacetamide (TAA)-induced } \\
\text { rats. }\end{array}$ \\
\hline
\end{tabular}


Table 2. Cont.

\begin{tabular}{|c|c|c|c|c|c|}
\hline Themes & References & $\begin{array}{l}\text { Types of } \\
\text { Study }\end{array}$ & $\begin{array}{l}\text { Types of Propolis } \\
\text { Extracts and/or } \\
\text { Propolis Bioactive } \\
\text { Compounds }\end{array}$ & $\begin{array}{c}\text { Geographic } \\
\text { Locations of } \\
\text { the Propolis } \\
\text { Source }\end{array}$ & Measured Outcome \\
\hline & [30] & $\begin{array}{l}\text { Animal } \\
\text { model (rats, } \\
n=120 \text { ) }\end{array}$ & $\begin{array}{l}\text { Hydroethanolic } \\
\text { extract } \\
200 \mathrm{mg} / \mathrm{kg} \mathrm{BW}\end{array}$ & Egypt & $\begin{array}{l}\text { Propolis reduced the adverse } \\
\text { effect of methotrexate by } \\
\text { reducing MDA and increasing } \\
\text { the activity of antioxidant } \\
\text { enzymes such as superoxide } \\
\text { dismutase (SOD), glutathione } \\
\text { peroxidase (GPx), and } \\
\text { glutathione reductase (GR), and } \\
\text { GSH. }\end{array}$ \\
\hline & [31] & $\begin{array}{l}\text { Animal } \\
\text { model (rats, } \\
n=40)\end{array}$ & $\begin{array}{l}\text { Propolis (extract } \\
\text { not specified) and } \\
\text { CAPE }\end{array}$ & Not specified & $\begin{array}{l}\text { Propolis and CAPE prevented } \\
\text { the increase in xanthine oxidase } \\
\text { activity, nitric oxide synthase } \\
\text { activity, nitric oxide (NO•) and } \\
\text { peroxynitrite (ONOO-) levels } \\
\text { in radiation-treated rats. }\end{array}$ \\
\hline & [32] & $\begin{array}{l}\text { Animal } \\
\text { model (rats, } \\
n=24)\end{array}$ & $\begin{array}{l}\text { Chrysin } \\
50 \mathrm{mg} / \mathrm{kg} \text { BW }\end{array}$ & Not specified & $\begin{array}{l}\text { In 3-Nitropropionic acid treated } \\
\text { rats, chrysin improved the } \\
\text { behavioral performance and } \\
\text { attenuated the oxidative stress } \\
\text { by maintaining the level of } \\
\text { antioxidant parameters and } \\
\text { reducing the oxidative stress } \\
\text { parameters. }\end{array}$ \\
\hline & [33] & $\begin{array}{l}\text { Animal } \\
\text { model (rats, } \\
n=\text { not } \\
\text { specified) }\end{array}$ & $\begin{array}{l}\text { Aqeuous extract } \\
100 \mathrm{mg} / \mathrm{kg} \text { BW }\end{array}$ & Turkey & $\begin{array}{l}\text { Propolis reversed the } \\
\text { scopolamine-induced cognitive } \\
\text { deterioration. }\end{array}$ \\
\hline & [34] & $\begin{array}{l}\text { Animal } \\
\text { model (rats, } \\
n=54)\end{array}$ & $\begin{array}{l}\text { Propolis (extract } \\
\text { not specified) } \\
80 \mathrm{mg} / \mathrm{kg} \mathrm{BW} \text { and } \\
\text { CAPE } 10 \mu \mathrm{mol} / \mathrm{kg} \\
\text { BW }\end{array}$ & Not specified & $\begin{array}{l}\text { Propolis prevented the increase } \\
\text { in MDA associated with } \\
\text { radiation toxicity. }\end{array}$ \\
\hline & [35] & $\begin{array}{l}\text { Cell cultures } \\
\text { (PC-12) }\end{array}$ & $\begin{array}{l}\text { CAPE } \\
1,5 \text { or } 10 \mu \mathrm{M}\end{array}$ & Not specified & $\begin{array}{l}\text { CAPE induced the formation of } \\
\text { synapses and neuritis, and } \\
\text { prevented the MPP+ } \\
\text { (1-methyl-4-phenylpyridinium) } \\
\text { cytotoxicity by increasing the } \\
\text { expression of increases the } \\
\text { expression of GAP-43, synapsin } \\
\text { and synaptophysin. }\end{array}$ \\
\hline & {$[36]$} & $\begin{array}{l}\text { Animal } \\
\text { model (rats, } \\
n=24 \text { ) }\end{array}$ & $\begin{array}{l}\text { Hydroethanolic } \\
150 \mathrm{mg} / \mathrm{kg} \mathrm{BW}\end{array}$ & Malaysia & $\begin{array}{l}\text { Propolis inhibited the } \\
\text { expression of NOS, NO, TNF- } \alpha \\
\text { and caspase- } 3 \text { in the cerebral } \\
\text { cortex (CC), cerebellum (CB) } \\
\text { and brain stem (BS) of kainic } \\
\text { acid-induced rats. }\end{array}$ \\
\hline
\end{tabular}


Table 2. Cont.

\begin{tabular}{|c|c|c|c|c|c|}
\hline Themes & References & $\begin{array}{l}\text { Types of } \\
\text { Study }\end{array}$ & $\begin{array}{l}\text { Types of Propolis } \\
\text { Extracts and/or } \\
\text { Propolis Bioactive } \\
\text { Compounds }\end{array}$ & $\begin{array}{l}\text { Geographic } \\
\text { Locations of } \\
\text { the Propolis } \\
\text { Source }\end{array}$ & Measured Outcome \\
\hline & [37] & $\begin{array}{l}\text { Animal } \\
\text { model (rats, } \\
n=40 \text { ) }\end{array}$ & $\begin{array}{l}\text { Not specified } \\
50 \mathrm{mg} / \mathrm{kg} \mathrm{BW}\end{array}$ & Not specified & $\begin{array}{l}\text { Propolis attenuated } \\
\text { chlorpyrifos-induced toxicity. } \\
\text { Propolis reduced the activity of } \\
\text { serum and brain cholinesterase } \\
\text { induced by chlorpyrifos. Propolis } \\
\text { also inhibited the increase in glial } \\
\text { fibrillary acidic protein-expression. }\end{array}$ \\
\hline & [38] & $\begin{array}{l}\text { Animal } \\
\text { model (rats, } \\
n=78)\end{array}$ & $\begin{array}{l}\text { Not specified } \\
150 \mathrm{mg} / \mathrm{kg} \mathrm{BW}\end{array}$ & Egypt & $\begin{array}{l}\text { In endotoxin-treated rats, propolis } \\
\text { attenuated the decrease in the level } \\
\text { of norepinehrine (NE), dopamine } \\
\text { (DA) and 5-hydroxytryptamine } \\
\text { (serotonin, 5-HT) in both } \\
\text { thalamus-hypothalamus and } \\
\text { cerebellum. }\end{array}$ \\
\hline \multirow{6}{*}{$\begin{array}{l}\text { Alzheimer's } \\
\text { disease model }\end{array}$} & [39] & In vitro & $\begin{array}{l}\text { Hydroethanolic } \\
\text { extract } \\
1: 10(w / v)\end{array}$ & Iran & $\begin{array}{l}\text { Propolis inhibited amyloid } \\
\text { fibrillation. }\end{array}$ \\
\hline & {$[40]$} & In vitro & $\begin{array}{l}\text { Essential oils of } \\
\text { propolis }\end{array}$ & Cameroon & $\begin{array}{l}\text { Components of propolis essential } \\
\text { oil exhibited anti-cholinesterase } \\
\text { activity. }\end{array}$ \\
\hline & [41] & In vitro & $\begin{array}{l}\text { Essential oils and } \\
\text { methanolic extract } \\
\mathrm{IC}_{50} \text { value: } 20-35 \\
\mu \mathrm{g} / \mathrm{mL}\end{array}$ & Algeria & $\begin{array}{l}\text { Components of propolis essential } \\
\text { oil and methanolic extract of } \\
\text { propolis exhibited } \\
\text { anti-cholinesterase activity against } \\
\text { both acetylcholinesterase and } \\
\text { butyrylcholinesterase. }\end{array}$ \\
\hline & [42] & $\begin{array}{l}\text { Animal } \\
\text { model (rats, } \\
n=56)\end{array}$ & $\begin{array}{l}\text { Ethanolic extract } \\
100,200,300 \\
\mathrm{mg} / \mathrm{kg} \mathrm{BW}\end{array}$ & India & $\begin{array}{l}\text { Propolis reduced the severity of the } \\
\text { cognitive impairment in the } \\
\beta \text {-amyloid induced rats. Propolis } \\
\text { improved the antioxidant status, } \\
\text { brain monoamines, and } \\
\text { brain-derived neurotrophic factor. } \\
\text { Propolis inhibited the activity of } \\
\text { acetylcholinesterase activity in a } \\
\text { dose-dependent manner. }\end{array}$ \\
\hline & [43] & In vitro & $\begin{array}{l}\text { CAPE } \\
\mathrm{Ki}=322.02 \text { pM to } \\
4.467 \mu \mathrm{M}\end{array}$ & Not specified & $\begin{array}{l}\text { Inhibition of the activity of } \\
\text { acetylcholinesterase and } \\
\text { butyrylcholinesterase. }\end{array}$ \\
\hline & [44] & $\begin{array}{l}\text { Animal } \\
\text { model (mice, } \\
n=48)\end{array}$ & $\begin{array}{l}\text { Pinocembrin } \\
20 \text { and } 40 \mathrm{mg} / \mathrm{kg} \\
\text { BW }\end{array}$ & Not specified & $\begin{array}{l}\text { Pinocembrin inhibited the } \\
\text { expression of receptor for advanced } \\
\text { glycation end-products (RAGE) } \\
\text { and its downstream inflammatory } \\
\text { signaling pathway markers such as } \\
\text { p38 mitogen-activated protein } \\
\text { kinase (MAPK), protein kinase } \\
\text { (SAPK)/c-Jun N-terminal kinase } \\
\text { (JNK), and NF-kB. Pinocembrin } \\
\text { also exhibited } \\
\text { mitochondrial-protective } \\
\text { properties. }\end{array}$ \\
\hline
\end{tabular}


Table 2. Cont.

\begin{tabular}{|c|c|c|c|c|c|}
\hline Themes & References & $\begin{array}{l}\text { Types of } \\
\text { Study }\end{array}$ & $\begin{array}{l}\text { Types of Propolis } \\
\text { Extracts and/or } \\
\text { Propolis Bioactive } \\
\text { Compounds }\end{array}$ & $\begin{array}{c}\text { Geographic } \\
\text { Locations of } \\
\text { the Propolis } \\
\text { Source }\end{array}$ & Measured Outcome \\
\hline \multirow{5}{*}{$\begin{array}{l}\text { Parkinson's } \\
\text { disease model }\end{array}$} & {$[45]$} & $\begin{array}{l}\text { Animal } \\
\text { model } \\
\text { (Drosophila } \\
\text { melanogaster, } \\
n=\text { not } \\
\text { specified) }\end{array}$ & $\begin{array}{l}\text { Ethanolic extract } \\
250 \text { and } \\
500 \mathrm{mg} / \mathrm{mL}\end{array}$ & Not specified & $\begin{array}{l}\text { Propolis improved motor activity, } \\
\text { antioxidant status, and lifespan. }\end{array}$ \\
\hline & [46] & $\begin{array}{l}\text { Animal } \\
\text { model (rats, } \\
n=21)\end{array}$ & $\begin{array}{l}\text { Not specified } \\
200 \mathrm{mg} / \mathrm{kg} \mathrm{BW}\end{array}$ & Brazil & $\begin{array}{l}\text { Propolis inhibited neuronal loss in } \\
\text { the substantia nigra and attenuated } \\
\text { striatal fiber degeneration in } \\
\text { 6-hydroxydopamine } \\
\text { (6-OHDA)-induced rats. }\end{array}$ \\
\hline & [47] & $\begin{array}{l}\text { Animal } \\
\text { model (rats, } \\
n=48)\end{array}$ & $\begin{array}{l}\text { Hydroethanolic } \\
\text { extract of propolis } \\
(10 \text { and } 50 \mathrm{mg} / \mathrm{kg} \\
\text { BW) and } \\
\text { Formononetin }(10 \\
\text { and } 20 \mathrm{mg} / \mathrm{kg} \mathrm{BW})\end{array}$ & Brazil & $\begin{array}{l}\text { Propolis and one of its bioactive } \\
\text { compound, formononetin reduced } \\
\text { the neuron loss and motor } \\
\text { impairment in 6-OHDA-induced } \\
\text { rats. }\end{array}$ \\
\hline & [48] & $\begin{array}{l}\text { Animal } \\
\text { model (rats, } \\
n=70 \text { ) }\end{array}$ & $\begin{array}{l}\text { Aqueous extract } \\
1: 5(w / v)\end{array}$ & Iran & $\begin{array}{l}\text { Propolis improved the antioxidant } \\
\text { status in terms of SOD and GPx } \\
\text { activities and ferric reducing ability } \\
\text { of plasma in 6-OHDA-induced rats. } \\
\text { Propolis also appeared to protect } \\
\text { tyrosine hydroxylase neurons. }\end{array}$ \\
\hline & [49] & $\begin{array}{l}\text { Animal } \\
\text { model } \\
\text { (rats, } n=18)\end{array}$ & $\begin{array}{l}\text { CAPE } \\
10 \mu \mathrm{mol} / \mathrm{kg} \mathrm{BW}\end{array}$ & $\begin{array}{l}\text { Not } \\
\text { determined }\end{array}$ & $\begin{array}{l}\text { CAPE prevented the dopaminergic } \\
\text { neuronal loss induced by 6-OHDA } \\
\text { in rats. CAPE also prevented } \\
\text { mitochondrial permeability } \\
\text { transition (neuronal death } \\
\text { mediator) }\end{array}$ \\
\hline \multirow{5}{*}{ Cytotoxicity } & {$[50]$} & $\begin{array}{l}\text { Cell cultures } \\
\text { (glioblas- } \\
\text { toma) }\end{array}$ & $\begin{array}{l}\text { Hydroethanolic } \\
\text { extract }\end{array}$ & Turkey & $\begin{array}{l}\text { Propolis reduced the expression of } \\
\text { oncogenic miRNAs associated with } \\
\text { glioblastoma. }\end{array}$ \\
\hline & [51] & $\begin{array}{l}\text { Cell cultures } \\
\text { (glioblas- } \\
\text { toma) }\end{array}$ & $\begin{array}{l}\text { Propolis extracted } \\
\text { in Lavender oil } \\
1: 10(w / v)\end{array}$ & Turkey & $\begin{array}{l}\text { Cytotoxic activity against } \\
\text { glioblastoma cells. }\end{array}$ \\
\hline & [52] & $\begin{array}{l}\text { Cell cultures } \\
\text { (rat primary } \\
\text { astrocytes) }\end{array}$ & $\begin{array}{l}\text { Hydroethanolic } \\
\text { extract } \\
10,25, \text { or } \\
100 \mu \mathrm{g} / \mathrm{ml}\end{array}$ & Turkey & $\begin{array}{l}\text { Dose-dependent cytotoxicity on } \\
\text { astrocytes was observed. Propolis } \\
\text { inducedcytoskeletonrearrange- } \\
\text { ments and pro-apoptotic signaling } \\
\text { pathways; NF-kB and poly } \\
\text { (ADP-ribose) polymerase (PARP). }\end{array}$ \\
\hline & [53] & $\begin{array}{l}\text { Animal } \\
\text { model (mice, } \\
n=\text { not } \\
\text { specified) }\end{array}$ & $\begin{array}{l}\text { Ethanolic extract } \\
\text { up to } 1000 \mathrm{mg} / \mathrm{kg} \\
\text { BW }\end{array}$ & India & $\begin{array}{l}\text { High concentration of propolis } \\
\text { extract up to } 1000 \mathrm{mg} / \mathrm{kg} \text { BW did } \\
\text { not negatively affect the histological } \\
\text { appearance of organs, including the } \\
\text { brain. }\end{array}$ \\
\hline & {$[54]$} & $\begin{array}{l}\text { Cell cultures } \\
\text { (astroglia cell } \\
\text { line/SVGp12) }\end{array}$ & $\begin{array}{l}\text { Ethanolic extract } \\
10-100 \mu \mathrm{g} / \mathrm{mL} \\
\text { CAPE and Chrysin } \\
5-50 \mu \mathrm{M}\end{array}$ & Poland & $\begin{array}{l}\text { Propolis and its bioactive } \\
\text { compounds reduced the viability of } \\
\text { astroglial cells. }\end{array}$ \\
\hline
\end{tabular}


Table 2. Cont.

\begin{tabular}{|c|c|c|c|c|c|}
\hline Themes & References & $\begin{array}{l}\text { Types of } \\
\text { Study }\end{array}$ & $\begin{array}{l}\text { Types of Propolis } \\
\text { Extracts and/or } \\
\text { Propolis Bioactive } \\
\text { Compounds }\end{array}$ & $\begin{array}{l}\text { Geographic } \\
\text { Locations of } \\
\text { the Propolis } \\
\text { Source }\end{array}$ & Measured Outcome \\
\hline \multirow{4}{*}{$\begin{array}{l}\text { Cognitive } \\
\text { Improvement }\end{array}$} & [55] & $\begin{array}{l}\text { Randomized, } \\
\text { placebo- } \\
\text { controlled } \\
\text { trial }(n=79)\end{array}$ & $\begin{array}{l}\text { Dietary } \\
\text { supplement } \\
\text { containing } \\
\text { propolis extract. } \\
\text { Types of extract } \\
\text { not specified } \\
6 \text { capsules of } \\
\text { propolis extract } \\
\text { containing } \\
\text { artepillin C, } \\
57.68 \mathrm{mg} \text {; culifolin, } \\
0.95 \mathrm{mg}\end{array}$ & Not specified & $\begin{array}{l}\text { Propolis significantly improved } \\
\text { verbal memory and information } \\
\text { processing speed (Cognitrax). } \\
\text { Propolis also improved serum total } \\
\text { cholesterol, LDL cholesterol, urea } \\
\text { nitrogen, creatinine, and uric acid. }\end{array}$ \\
\hline & [56] & $\begin{array}{l}\text { Animal } \\
\text { model (rats, } n \\
=40)\end{array}$ & $\begin{array}{l}\text { Aqueous extract } \\
100 \mathrm{mg} / \mathrm{kg} \mathrm{BW}\end{array}$ & Turkey & $\begin{array}{l}\text { Propolis reversed the transfer } \\
\text { latency parameter associated with } \\
\text { physiological aging in rats. Transfer } \\
\text { latency is defined as the time taken } \\
\text { by the animals to move from the } \\
\text { open arm to the enclosed arm of an } \\
\text { experimental compartment. }\end{array}$ \\
\hline & [57] & $\begin{array}{l}\text { Randomized, } \\
\text { placebo- } \\
\text { controlled } \\
\text { trial }(n=80)\end{array}$ & $\begin{array}{l}\text { Propolis dietary } \\
\text { supplement (types } \\
\text { of extract not } \\
\text { specified) } \\
0.33 \mathrm{~g}\end{array}$ & Brazil & $\begin{array}{l}\text { Propolis improved cognitive } \\
\text { function measured by Mini-Mental } \\
\text { State Examination (MMSE) and } \\
\text { Alzheimer Disease Assessment } \\
\text { Scale-cognitive subscale } \\
\text { (ADAS-cog). Propolis reduced } \\
\text { serum level of IL-6 and TGF } \beta 1 .\end{array}$ \\
\hline & [58] & $\begin{array}{l}\text { Randomized, } \\
\text { placebo- } \\
\text { controlled } \\
\text { trial }(n=87)\end{array}$ & $\begin{array}{l}\text { Propolis dietary } \\
\text { supplement } \\
\text { (Extract not } \\
\text { specified) }\end{array}$ & Brazil & $\begin{array}{l}\text { Propolis improved cognitive } \\
\text { function measured by MMSE and } \\
\text { reduced the serum level of hs-CRP } \\
\text { and LDL. }\end{array}$ \\
\hline \multirow{3}{*}{$\begin{array}{l}\text { Regenerative } \\
\text { medicine }\end{array}$} & [59] & $\begin{array}{l}\text { Animal } \\
\text { model (mice, } \\
n=24)\end{array}$ & $\begin{array}{l}\text { Implantation of an } \\
\text { artificial guidance } \\
\text { channel containing } \\
\text { whole propolis } \\
\text { combined with } \\
\text { Gum Arabic. }\end{array}$ & Iran & $\begin{array}{l}\text { Propolis-gum Arabic graft } \\
\text { increased the mean number of } \\
\text { muscle fiber diameters and } \\
\text { myelinated axons. }\end{array}$ \\
\hline & {$[60]$} & \multicolumn{2}{|c|}{ 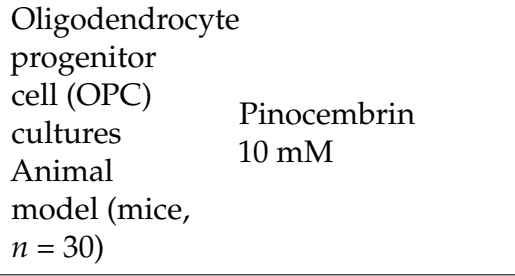 } & Not specified & $\begin{array}{l}\text { Pinocembrin induced the OPC } \\
\text { differentiation and remyelination } \\
\text { through the phosphorylated mTOR } \\
\text { pathway in multiple sclerosis } \\
\text { disease model. }\end{array}$ \\
\hline & [61] & $\begin{array}{l}\text { Cell cultures } \\
\text { (BV2 cells } \\
\text { and primary } \\
\text { microglia } \\
\text { cells) } \\
\text { Animal } \\
\text { model (mice, } \\
n=16 \text { ) }\end{array}$ & $\begin{array}{l}\text { Chrysin } \\
5,10 \text {, and } 20 \mu \mathrm{M}\end{array}$ & Not specified & $\begin{array}{l}\text { Chrysin inhibited the inflammation } \\
\text { of LPS-induced BV2, primary } \\
\text { microglial cells, and mice by } \\
\text { upregulating the expression of } \\
\text { zinc-finger protein A20. }\end{array}$ \\
\hline
\end{tabular}


Table 2. Cont

\begin{tabular}{|c|c|c|c|c|c|}
\hline Themes & References & $\begin{array}{l}\text { Types of } \\
\text { Study }\end{array}$ & $\begin{array}{l}\text { Types of Propolis } \\
\text { Extracts and/or } \\
\text { Propolis Bioactive } \\
\text { Compounds }\end{array}$ & $\begin{array}{l}\text { Geographic } \\
\text { Locations of } \\
\text { the Propolis } \\
\text { Source }\end{array}$ & Measured Outcome \\
\hline \multirow{7}{*}{$\begin{array}{l}\text { Neuroinfla- } \\
\text { mmation, Pain, } \\
\text { and Oxidative } \\
\text { stress }\end{array}$} & [62] & $\begin{array}{l}\text { Animal } \\
\text { model (rats, } \\
n=18)\end{array}$ & $\begin{array}{l}\text { Aqueous extract } \\
100 \text { and } 200 \mathrm{mg} / \mathrm{kg} \\
\text { BW }\end{array}$ & Not specified & $\begin{array}{l}\text { Propolis decreased the expression } \\
\text { of } B a x \text { and reduced the number of } \\
\text { neurons in the hippocampal CA1 } \\
\text { area of sodium nitrite-induced rats. }\end{array}$ \\
\hline & {$[63]$} & $\begin{array}{l}\text { Cell cultures } \\
\text { (bEnd.3) }\end{array}$ & $\begin{array}{l}\text { Chrysin } \\
10,30 \text {, and } 100 \mu \mathrm{M}\end{array}$ & Not specified & $\begin{array}{l}\text { Chrysin reduced the expression of } \\
\text { vascular cell adhesion molecule-1 } \\
\text { (VCAM-1), Nuclear factor- } k B \\
\text { (NF-kB), p38 mitogen-activated } \\
\text { protein kinase (MAPK), and c-Jun } \\
\text { N-terminal kinase in the } \\
\text { LPS-induced bEnd.3 cells. Chrysin } \\
\text { also prevented the adhesion of } \\
\text { monocytes to the LPS-induced } \\
\text { bEnd. } 3 \text { cells. }\end{array}$ \\
\hline & {$[64]$} & $\begin{array}{l}\text { Cell culture } \\
\text { (microglia) } \\
\text { and animal } \\
\text { model (mice, } \\
n=\text { not } \\
\text { specified) }\end{array}$ & $\begin{array}{l}\text { Not specified } \\
50 \mu \mathrm{g} / \mathrm{mL}\end{array}$ & Brazil & $\begin{array}{l}\text { Propolis inhibit the cytotoxicity and } \\
\text { the expression of pro-inflammatory } \\
\text { biomarkers; IL- } 1 \beta, \text { TNF- } \alpha \text {, IL- } 6 \text {, } \\
\text { and 8-oxo-deoxyguanosine } \\
\text { following hypoxia exposure. } \\
\text { Propolis also significantly reduced } \\
\text { the hypoxia-induced generation of } \\
\text { reactive oxygen species (ROS) in the } \\
\text { mitochondria and downregulated } \\
\text { the expression of nuclear factor- } \mathrm{kB} \\
(\mathrm{NF}-\mathrm{kB} \text { ) in microglia. }\end{array}$ \\
\hline & {$[65]$} & $\begin{array}{l}\text { Animal } \\
\text { model (mice, } \\
n=180 ; \text { rats, } \\
n=36)\end{array}$ & $\begin{array}{l}\text { Hydroethanolic } \\
\text { extract of propolis } \\
3,10, \text { and } \\
30 \mathrm{mg} / \mathrm{kg} \mathrm{BW} \\
\text { and formononetin } \\
10 \mathrm{mg} / \mathrm{kg} \mathrm{BW}\end{array}$ & Brazil & $\begin{array}{l}\text { Propolis and formononetin } \\
\text { demonstrated anti-inflammatory } \\
\text { activity. Propolis and formononetin } \\
\text { inhibited oedema response and } \\
\text { carrageenan-induced leukocyte } \\
\text { migration during inflammatory } \\
\text { process. } \\
\text { Propolis was also shown to have } \\
\text { antinoceptive properties on } \\
\text { inflammatory and neurogenic pain. }\end{array}$ \\
\hline & [66] & $\begin{array}{l}\text { Animal } \\
\text { model (rats } \\
\text { and mice, } \\
n=20 \text { ) }\end{array}$ & $\begin{array}{l}\text { Aqueous extract } \\
1,2.5 \text {, abd } 5 \%(w / v)\end{array}$ & Morocco & $\begin{array}{l}\text { Propolis exhibited both central and } \\
\text { peripheral antinociceptive } \\
\text { activities. }\end{array}$ \\
\hline & [67] & $\begin{array}{l}\text { Cell cultures } \\
\text { (microglia) } \\
\text { and mice, } \\
n=9 \text { ) }\end{array}$ & $\begin{array}{l}\text { Ethanolic extract } \\
5,50, \text { and } \\
500 \mu \mathrm{g} / \mathrm{mL}\end{array}$ & Brazil & $\begin{array}{l}\text { Propolis reduced the expression of } \\
\text { oxidative markers IL- } 1 \beta, \text { TNF- } \alpha \text {, } \\
\text { IL-6, and 8-oxo-deoxyguanosine. } \\
\text { Propolis also reduced the } \\
\text { production of ROS in mitochondria. }\end{array}$ \\
\hline & [68] & $\begin{array}{l}\text { Animal } \\
\text { model (mice, } \\
n=36)\end{array}$ & $\begin{array}{l}\text { Ethanolic extract } \\
1 \mathrm{mM}\end{array}$ & Brazil & $\begin{array}{l}\text { Propolis exhibited antinoceptive } \\
\text { properties by modulating the } \\
\text { expression of IL- } 1 \beta \text { and TNF- } \alpha \text {. }\end{array}$ \\
\hline Epilepsy model & [69] & $\begin{array}{l}\text { Animal } \\
\text { model (rats, } \\
n=50)\end{array}$ & $\begin{array}{l}\text { Aqueous extract } \\
0.012 \mathrm{mg} / \mathrm{kg} \mathrm{BW}\end{array}$ & Turkey & $\begin{array}{l}\text { Propolis increased the } \\
\text { histopathological score of the } \\
\text { hippocampus and motor/cognitive } \\
\text { score in the lithium and } \\
\text { pilocarpine-induced rats. }\end{array}$ \\
\hline
\end{tabular}


Table 2. Cont.

\begin{tabular}{|c|c|c|c|c|c|}
\hline Themes & References & $\begin{array}{l}\text { Types of } \\
\text { Study }\end{array}$ & $\begin{array}{l}\text { Types of Propolis } \\
\text { Extracts and/or } \\
\text { Propolis Bioactive } \\
\text { Compounds }\end{array}$ & $\begin{array}{l}\text { Geographic } \\
\text { Locations of } \\
\text { the Propolis } \\
\text { Source }\end{array}$ & Measured Outcome \\
\hline & {$[70]$} & $\begin{array}{l}\text { Animal } \\
\text { model (rats, } n \\
=21 \text { ) }\end{array}$ & $\begin{array}{l}\text { CAPE } \\
30 \mathrm{mg} / \mathrm{kg} \mathrm{BW}\end{array}$ & $\begin{array}{l}\text { Not } \\
\text { determined }\end{array}$ & $\begin{array}{l}\text { CAPE significantly protected the } \\
\text { number of neurons in the CA1, } \\
\text { CA3, and dentate gyrus regions of } \\
\text { the hippocampus and the prefrontal } \\
\text { cortex. Apoptosis in the } \\
\text { hippocampus and the prefrontal } \\
\text { cortex was also inhibited by CAPE. }\end{array}$ \\
\hline \multirow{5}{*}{$\begin{array}{l}\text { Depression and } \\
\text { Stress models }\end{array}$} & [71] & $\begin{array}{l}\text { Animal } \\
\text { model (rats, } n \\
=40 \text { ) }\end{array}$ & $\begin{array}{l}\text { Aqueous extract } \\
100 \mathrm{mg} / \mathrm{kg} \mathrm{BW}\end{array}$ & Turkey & $\begin{array}{l}\text { In chronic unpredictable mild stress } \\
\text { (CUMS)-induced rats, propolis } \\
\text { exhibited anti-depressant } \\
\text { properties. Propolis also reduced } \\
\text { the level of corticosterone level and } \\
\text { reversed cognitive impairments. }\end{array}$ \\
\hline & [72] & $\begin{array}{l}\text { Animal } \\
\text { model (rats, } n \\
=24)\end{array}$ & $\begin{array}{l}\text { Not specified } \\
100 \text { and } 200 \mathrm{mg} / \mathrm{kg} \\
\text { BW }\end{array}$ & Not specified & $\begin{array}{l}\text { Propolis prevented the } \\
\text { hippocampal areaneuronal loss } \\
\text { associated with stress. }\end{array}$ \\
\hline & [73] & $\begin{array}{l}\text { Animal } \\
\text { model (mice, } \\
n=42)\end{array}$ & $\begin{array}{l}\text { Chrysin } \\
5 \text { and } 20 \mathrm{mg} / \mathrm{kg} \\
\text { BW }\end{array}$ & Not specified & $\begin{array}{l}\text { Chrysin reduced the elevation of } \\
\text { corticotropin-releasing and } \\
\text { adrenocorticotropic hormones, and } \\
\text { tumor necrosis factor- } \alpha \text {, } \\
\text { interleukin- } 1 \beta \text {, interleukin- } 6 \text { and } \\
\text { kynurenine levels in the prefrontal } \\
\text { cortex (PFC) and hippocampus } \\
\text { (HP) in mice exposed to } \\
\text { unpredictable chronic stress. }\end{array}$ \\
\hline & {$[74]$} & $\begin{array}{l}\text { Animal } \\
\text { model (mice, } \\
n=40)\end{array}$ & $\begin{array}{l}\text { Chrysin } \\
5 \text { or } 20 \mathrm{mg} / \mathrm{kg} \mathrm{BW}\end{array}$ & Not specified & $\begin{array}{l}\text { Chrysin alleviated behavioral } \\
\text { modification following olfactory } \\
\text { bulbectomy. Chrysin attenuated the } \\
\text { alterations of biochemical markers } \\
\text { associated with depressive } \\
\text { behavior, namely tumor necrosis } \\
\text { factor- } \alpha \text {, interferon- } \gamma \text {, } \\
\text { interleukin-1 } \beta \text {, interleukin- } 6 \text {, } \\
\text { kynurenine (KYN) levels, } \\
\text { indoleamine-2,3-dioxygenase } \\
\text { activity,5-hydroxytryptamine } \\
\text { (5-HT), brain-derived neurotrophic } \\
\text { factor (BDNF), KYN/tryptophan } \\
\text { and 5-hydroxyindoleacetic } \\
\text { acid/5-HT ratio. }\end{array}$ \\
\hline & [75] & $\begin{array}{l}\text { Animal } \\
\text { model (mice, } \\
n=28)\end{array}$ & $\begin{array}{l}\text { CAPE } \\
5,10, \text { and } \\
20 \mu \mathrm{mol} / \mathrm{kg}\end{array}$ & Not specified & $\begin{array}{l}\text { CAPE exhibited anti-depressant } \\
\text { activity on the animals. CAPE also } \\
\text { reduced CAPE significantly } \\
\text { decreased glucocorticoid receptor } \\
\text { (GR) phosphorylation at S234 } \\
\text { (pGR(S234)). }\end{array}$ \\
\hline
\end{tabular}


Table 2. Cont.

\begin{tabular}{|c|c|c|c|c|c|}
\hline Themes & References & $\begin{array}{l}\text { Types of } \\
\text { Study }\end{array}$ & $\begin{array}{l}\text { Types of Propolis } \\
\text { Extracts and/or } \\
\text { Propolis Bioactive } \\
\text { Compounds }\end{array}$ & $\begin{array}{l}\text { Geographic } \\
\text { Locations of } \\
\text { the Propolis } \\
\text { Source }\end{array}$ & Measured Outcome \\
\hline & [76] & $\begin{array}{l}\text { Animal } \\
\text { model (mice, } \\
n=50)\end{array}$ & $\begin{array}{l}\text { Hydroethanolic } \\
\text { extract } \\
50,100 \text {, and } \\
200 \mathrm{mg} / \mathrm{kg} \mathrm{BW}\end{array}$ & Korea & $\begin{array}{l}\text { Propolis exhibited anti-depressant } \\
\text { activity by increasing the } \\
\text { expression of hippocampal } \\
\text { glucocorticoid receptor. Propolis } \\
\text { also increased pGR(S220)/(S234) } \\
\text { ratio. Propolis upregulated the } \\
\text { cAMP-responsive element binding } \\
\text { protein phosphorylation at S133 } \\
\text { (pCREB). }\end{array}$ \\
\hline Adverse effects & [77] & Case report & $\begin{array}{l}\text { Not specified } \\
50 \text { g/day for } \\
3 \text { days }\end{array}$ & Turkey & $\begin{array}{l}\text { Propolis appeared to induce } \\
\text { psychotic episodes in a thirty four } \\
\text { year old male. }\end{array}$ \\
\hline Others & [78] & $\begin{array}{l}\text { Cell cultures } \\
\text { (rat brain mi- } \\
\text { crovascular } \\
\text { endothelial } \\
\text { cells) }\end{array}$ & $\begin{array}{l}\text { Pinocembrin } \\
5,20, \text { and } \\
40 \mu \mathrm{g} / \mathrm{mL}\end{array}$ & Not specified & $\begin{array}{l}\text { Pinocembrin appeared to cross } \\
\text { blood-brain barrier cell model } \\
\text { without affecting the function and } \\
\text { expression of p-glycoprotein. }\end{array}$ \\
\hline
\end{tabular}

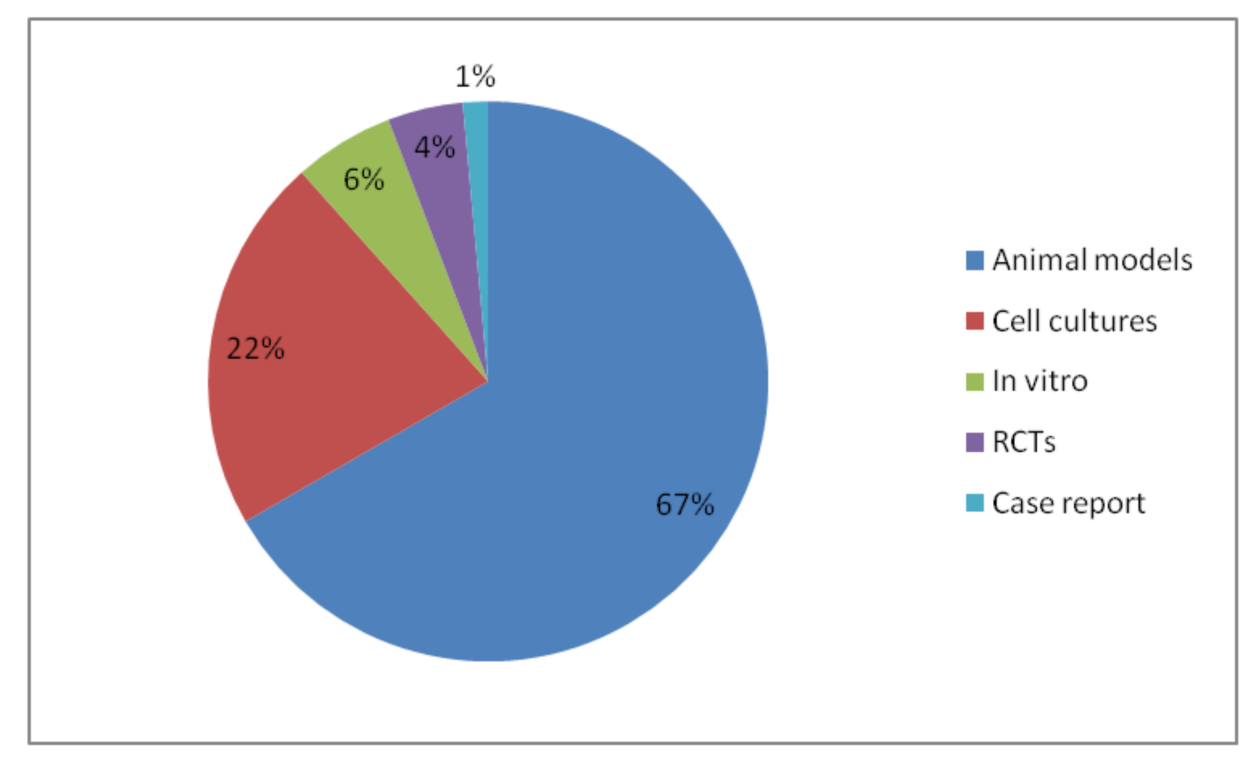

Figure 2. The percentages of the types of studies investigating the therapeutic use of propolis in the brain and in neurological disorders and injuries.

Moreover, Figure 3 illustrates the types of propolis extracts used in the studies, namely hydroethanolic $(29 \%)$, ethanolic $(16 \%)$, aqueous extract $(18 \%)$, methanolic $(2 \%)$, propolis essential oils (4\%), and unspecified/other forms (31\%). These organic solvents are widely used because of their affinity with lipophilic and hydrophilic bioactive molecules, such as phenolics; among them, ethanol is the preferred one because it is non-toxic, economical, and reusable [79]. 


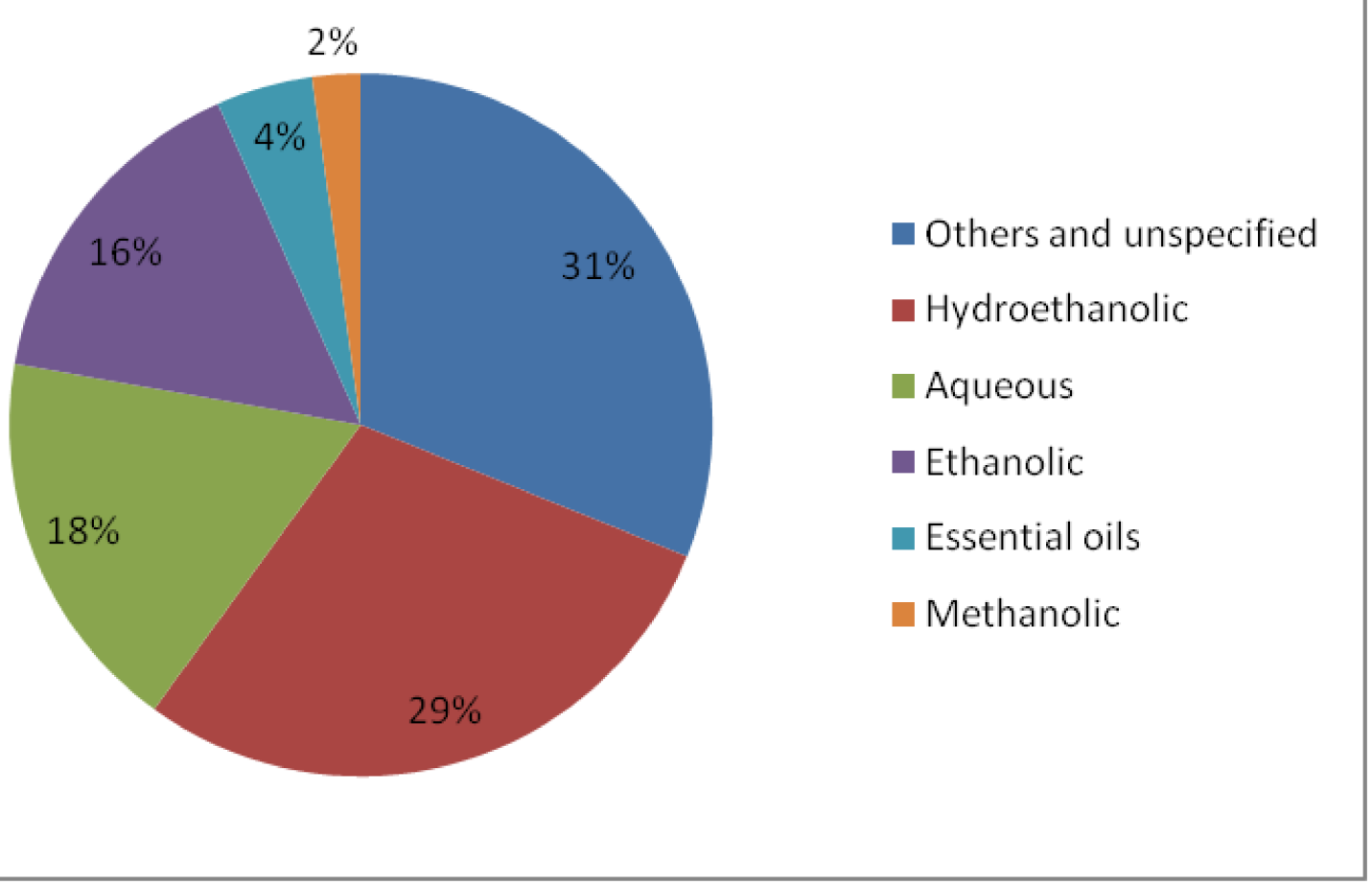

Figure 3. The types of propolis extract used in the included studies.

Table 3 illustrates the geographic locations of the propolis sources and bioactive compounds where whole propolis was not used in the studies; Egypt (6\%), Algeria (1\%), Cameroon (1\%), Morocco (1\%), Turkey (14\%), Iran (7\%), Poland (1\%), Korea (1\%), India $(3 \%)$, Indonesia (1\%), Malaysia (1\%), Brazil (10\%), unspecified $(19 \%)$, and other bioactive compounds $(30 \%)$. The percentages are rounded to the nearest whole number.

Table 3. The percentages of studies that utilize propolis bioactive compounds and/or the geographical locations of the propolis source in the included studies.

\begin{tabular}{ll}
\hline Geographical Sources of Propolis and/or Bioactive Compounds & Percentage (\%) \\
\hline Bioactive compounds & 30 \\
\hline Unspecified & 19 \\
\hline Turkey & 14 \\
\hline Brazil & 10 \\
\hline Iran & 7 \\
\hline Egypt & 6 \\
\hline India & 3 \\
\hline Algeria & 1 \\
\hline Morocco & 1 \\
\hline Cameroon & 1 \\
\hline Poland & 1 \\
\hline Korea & 1 \\
\hline Indonesia & 1 \\
\hline Malaysia & 1 \\
\hline
\end{tabular}




\section{Discussion}

The largest body of experimental evidence found in the present scoping review was in the detoxification theme. The therapeutic properties of propolis and its bioactive compounds appear to be due to their anti-inflammatory properties. In animals and cell cultures which were subjected to chemical and radiation toxicity, propolis was consistently demonstrated to reduce the expression of inflammatory and oxidative markers such as malonaldehyde (MDA), tumor necrosis factor- $\alpha$ (TNF- $\alpha$ ), nitric oxide (NO), and inducible nitric oxide synthase (iNOS), while increasing and maintaining antioxidant parameters, namely superoxide dismutase (SOD), glutathione peroxidase (GPx), glutathione reductase (GR), and glutathione (GSH) $[23,27,29-32,34,36]$. In addition, it inhibited apoptosis by reducing the expression of genes associated with apoptosis signaling pathways; protein-coding gene Bax, cytochrome-c, cas-3, cas-8, and p53 genes [24,25]. It was also evident that propolis protected cell membranes and prevented further deterioration of the tissue morphology associated with toxicity $[23,26,28,33,35,37]$.

The neuroprotective effect of propolis was also demonstrated in terms of alleviating symptoms associated with aneurysm, ischemia, ischemia-reperfusion and traumatic brain injuries. The anti-inflammatory properties of propolis were shown to play a significant role in attenuating the negative effect of these injuries. Propolis reduced the expression of interleukin-6 (IL-6), TNF- $\alpha$, matrix metalloproteinase-2 (MMP-2), MMP-9, monocyte chemotactic protein-1 (MCP-1), and iNOS, while increasing the expression of protective proteins such as heat shock protein-70 (hsp70) $[14,16-18,20]$. It also inhibited the development of histopathology associated with these injuries and in some cases promoted the development of myelinated fibers $[15,17,21]$. More importantly, propolis was shown to significantly ameliorate the impairment of sensory-motor and other physical indices in animals subjected to these injuries [15,18,21,22].

Unsurprisingly, propolis was shown to be effective in attenuating symptoms of neuroinflammation, pain, and oxidative stress. Propolis was consistently shown to reduce inflammation markers such as vascular cell adhesion molecule-1 (VCAM-1), nuclear factor kappa B (NF-kB), mitogen-activated protein kinase (MAPK), and c-Jun N-terminal kinase (JNK)-associated markers in artificially induced inflammation in both cell cultures and animal models. It also reduced the expression of reactive oxygen species (ROS) and pro-inflammatory cytokines such as IL-1 $\beta$, IL-6, and TNF- $\alpha[63,64,66-68]$. In one study, propolis was shown to prevent the migration of leukocytes into the inflammation site [65]. Propolis also appeared to upregulate the expression of zinc-finger protein A20 during inflammation; a novel anti-inflammatory mode of action of propolis [61].

Moreover, the anti-depressant properties of propolis were demonstrated in various animal model studies. Propolis reduced the level of corticosterone and adenocorticotropic hormones in stressed and depressed animals [71,74]. Apoptosis of neurons in the brain regions such as hippocampus and prefrontal cortex was also inhibited by propolis $[72,73]$. In addition, it modulated the expression of inflammatory markers such as TNF- $\alpha$, IL-1 $\beta$, IL-6, kynurenine (KYN) levels, indoleamine-2,3-dioxygenase activity,5-hydroxytryptamine (5-HT), brain-derived neurotrophic factor (BDNF), and glucocorticoid receptors [73-76]. The modulation of the endocrines and biochemical markers resulted in the attenuation of depressive behavior and cognitive impairment in the animals.

In the neurological and neurodegenerative disease models, namely Alzheimer's disease, Parkinson's disease, and epilepsy, propolis also showed potential therapeutic benefits. Propolis was demonstrated to reduce amyloid fibrillation and reduce the impact of amyloid accumulation $[39,42]$. In addition, propolis inhibited the activity of both acetylcholinesterase and butyrylcholinesterase in a dose-dependent manner [40-43]. In the Parkinson's disease and epilepsy models, propolis reduced neuronal loss and improved the histopathology associated with these diseases $[46,47,49,69,70]$. In all of these disease models, propolis consistently reduced the expression of inflammatory markers, maintained the antioxidant status, and improved motor/cognitive scores of the animals $[44,45,48,69]$. 
One study showed that propolis could potentially be used as an adjuvant for treating brain infection [13]. Nosratiyan et al. (2021) and Shao et al. (2021) demonstrated that propolis can be used in regenerative medicine as it induced axon myelination and oligodendrocyte progenitor cells (OPC) differentiation. Propolis was also shown to be cytotoxic towards cancerous brain cells, i.e., glioblastoma cells, astrocytes, and astroglial cells [50-52,54]. However, Kalia et al. (2014) observed no cytotoxicity in organs, including the brain of normal mice fed up to $1000 \mathrm{mg}$ propolis extract/ $\mathrm{kg}$ body weight.

Arguably, the most important studies were the translation of the therapeutic benefits of propolis into humans demonstrated in randomized, placebo-controlled clinical trials (RCTs). The present scoping review managed to identify three RCTs $(n=246$ subjects in total). Propolis was shown in all of these studies to improve cognitive function of geriatric subjects measured by various standardized tests; Cognitrax, MMSE, and ADAScog. The cognitive improvement appeared to be correlated to the improvement of the serum level of inflammatory markers such as IL-6, TGF $\beta 1$, hs-CRP, and serum level of other biochemical markers namely total cholesterol, LDL, urea, creatinine, and uric acid. No adverse event was recorded in these studies $[55,57,58]$. However, we identified a case report where propolis appeared to induce psychotic episodes in a thirty-four-year-old male in Turkey [77]. Based on various human clinical trials in other areas of propolis research, propolis appears to be generally safe in humans [9,80-84]. Figure 4 summarizes the potential use of propolis as an adjuvant therapy in brain and neurological disorders and injuries.

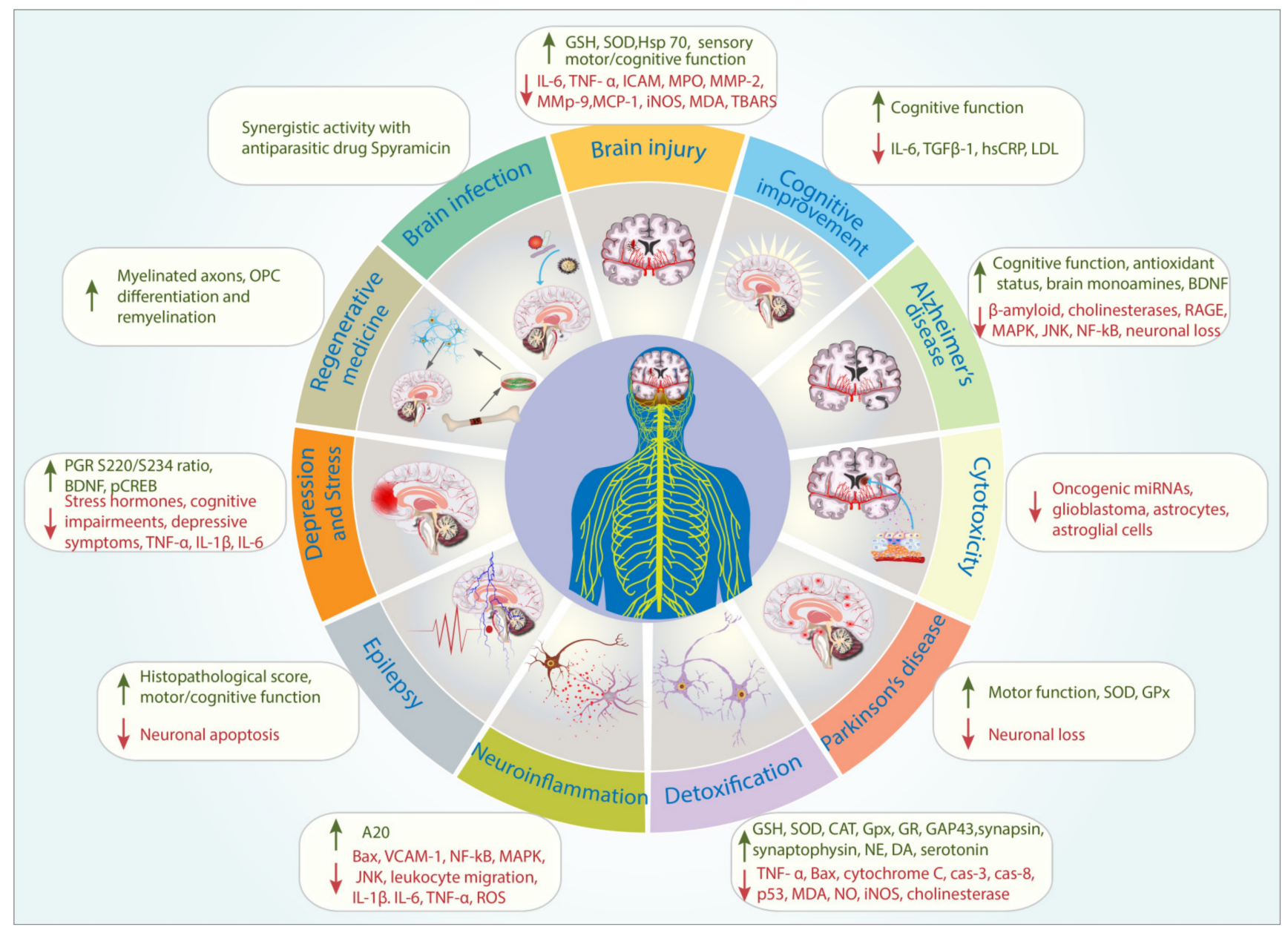

Figure 4. The potential use of propolis in treating brain and neurological injuries and disorders and its mode of action based on the latest experimental data. Green and red arrows indicate increased and reduced activity/expression, respectively. 
In the present review, the reviewers adopted a comprehensive and systematic search strategy in order to objectively fulfill the aim of the study. A broad range of studies from all fields of science and technology was collected and analyzed. The reviewers limited the search to studies that were published in the last 10 years, to provide coverage of the latest experimental evidence in the field. However, the reviewers only assessed and included English language articles, which could potentially lead to missing studies from non-English databases, as it is apparent most studies originated from non-English speaking countries. The reviewers also did not assess the quality of the included studies in order to include as many studies and to provide as broad coverage as possible. In addition, the reviewers did not perform meta-analysis as it is not appropriate due to the heterogeneity of the included studies.

\section{Future Directions and Concluding Remarks}

One of the main criticisms often aimed at natural product research is the lack of characterization of the main bioactive compounds. This can be found in the included studies as $31 \%$ of the studies did not provide clear identification of the types of propolis extract used. In addition, $19 \%$ of the studies did not indicate the geographical location of the propolis source. We propose that all future studies investigating the biological activities of propolis should include at least two pieces of information, namely the types of extract and clear geographical location of the propolis source. Basic chemical analyses, where possible, of the propolis extract, such as total phenolics and/or flavonoids, should be performed. These steps would standardize propolis research, significantly assist in replication studies, and further solidify the potential therapeutic uses of propolis.

In addition, studies that investigated the biological activities of propolis may refrain from concluding certain phenolics, flavonoids, or terpenoids that impart its biological activities, unless it was clearly demonstrated. It appears the therapeutic benefit of propolis may lie in the synergistic effect of various compounds rather than individual compounds [65]. Furthermore, the majority of propolis extracts used were extracted using organic solvents such as ethanol and methanol. Concerns with regard to chemical toxicity, contamination, religious and cultural reasons often arise due to the use of organic solvents for extraction purposes. Another promising area of research is the use of safer and greener chemical alternatives such as natural deep eutectic solvents (NADES), glycerol, and propylene glycol [85-87]. Moreover, the majority of the studies used propolis from a single species of bees; the European honey bee (Apis mellifera). Future research could also explore the potential therapeutic properties of propolis harvested from the hives of other bee species such as Apis cerana and Meliponini bees (stingless bees). In conclusion, the present scoping review demonstrates that propolis is a promising therapeutic substance, either as pharmaceuticals or nutraceuticals, for protecting the brain and treating neurological disorders and injuries.

Supplementary Materials: The following are available online at https:/ / www.mdpi.com/article/10 $.3390 /$ biomedicines 9091227 / s1, Table S1: Search strategy of the scoping review, Prisma checklist.

Author Contributions: Conceptualization, F.Z. and S.T.; methodology, F.Z. and S.T.; validation, C.O.P.; formal analysis, F.Z., C.O.P. and S.T.; writing-original draft preparation, F.Z. and S.T.; review and editing, C.O.P. All authors have read and agreed to the published version of the manuscript.

Funding: This research received no external funding and the APC was funded by KebunEfi.

Institutional Review Board Statement: Not applicable.

Informed Consent Statement: Not applicable.

Acknowledgments: We are thankful to Fuad Bahram for the production of Figure 4.

Conflicts of Interest: KebunEfi produces propolis extracts from Indonesian stingless bees. All other authors declare no conflict of interest. 


\section{References}

1. Dalenberg, H.; Maes, P.; Mott, B.; Anderson, K.E.; Spivak, M. Propolis envelope promotes beneficial bacteria in the honey bee (Apis mellifera) mouthpart microbiome. Insects 2020, 11, 453. [CrossRef]

2. Saelao, P.; Borba, R.S.; Ricigliano, V.; Spivak, M.; Simone-Finstrom, M. Honeybee microbiome is stabilized in the presence of propolis. Biol. Lett. 2020, 16, 20200003. [CrossRef]

3. Borba, R.S.; Klyczek, K.K.; Mogen, K.L.; Spivak, M. Seasonal benefits of a natural propolis envelope to honey bee immunity and colony health. J. Exp. Biol. 2015, 218, 3689-3699. [CrossRef] [PubMed]

4. Bankova, V.; Popova, M.; Trusheva, B. Propolis volatile compounds: Chemical diversity and biological activity: A review. Chem. Cent. J. 2014, 8, 28. [CrossRef] [PubMed]

5. Freires, I.A.; De Alencar, S.M.; Rosalen, P.L. A pharmacological perspective on the use of Brazilian Red Propolis and its isolated compounds against human diseases. Eur. J. Med. Chem. 2016, 110, 267-279. [CrossRef]

6. Rojczyk, E.; Klama-Baryła, A.; Łabuś, W.; Wilemska-Kucharzewska, K.; Kucharzewski, M. Historical and modern research on propolis and its application in wound healing and other fields of medicine and contributions by Polish studies. J. Ethnopharmacol. 2020, 262, 113159. [CrossRef] [PubMed]

7. Silveira, M.A.D.; De Jong, D.; Berretta, A.A.; dos Galvão, E.B.S.; Ribeiro, J.C.; Cerqueira-Silva, T.; Amorim, T.C.; da Conceição, L.F.M.R.; Gomes, M.M.D.; Teixeira, M.B.; et al. Efficacy of Brazilian green propolis (EPP-AF®) as an adjunct treatment for hospitalized COVID-19 patients: A randomized, controlled clinical trial. Biomed. Pharmacother. 2021, 138, 111526. [CrossRef]

8. Kosari, M.; Noureddini, M.; Khamechi, S.P.; Najafi, A.; Ghaderi, A.; Sehat, M.; Banafshe, H.R. The effect of propolis plus Hyoscyamus niger L. methanolic extract on clinical symptoms in patients with acute respiratory syndrome suspected to COVID19: A clinical trial. Phyther. Res. 2021, 35, 4000-4006. [CrossRef]

9. Zulhendri, F.; Chandrasekaran, K.; Kowacz, M.; Ravalia, M.; Kripal, K.; Fearnley, J.; Perera, C.O. Antiviral, Antibacterial, Antifungal, and Antiparasitic Properties of Propolis: A Review. Foods 2021, 10, 1360. [CrossRef]

10. Peters, M.D.J.; Godfrey, C.M.; Khalil, H.; McInerney, P.; Parker, D.; Soares, C.B. Guidance for conducting systematic scoping reviews. JBI Evid. Implement. 2015, 13, 141-146. [CrossRef]

11. Munn, Z.; Peters, M.D.J.; Stern, C.; Tufanaru, C.; McArthur, A.; Aromataris, E. Systematic review or scoping review? Guidance for authors when choosing between a systematic or scoping review approach. BMC Med. Res. Methodol. 2018, 18, 1-7. [CrossRef] [PubMed]

12. Moher, D.; Shamseer, L.; Clarke, M.; Ghersi, D.; Liberati, A.; Petticrew, M.; Shekelle, P.; Stewart, L.A.; Estarli, M.; Barrera, E.S.A.; et al. Preferred reporting items for systematic review and meta-analysis protocols (PRISMA-P) 2015 statement. Syst. Rev. 2015, 4, 1. [CrossRef]

13. Hegazi, A.G.; Toaleb, N.I.; El Fadaly, H.A.; Abdel-Rahman, E.H.; Barakat, A.M.A. In vivo-Cellular and Humoral Immune Response for Evaluation of Propolis Effect on Chronic Toxoplasmosis in Rats. Adv. Anim. Vet. Sci. 2021, 9, 1045-1052. [CrossRef]

14. Günday, M.; Saritaş, Z.K.; Demirel, H.H.; Bülbül, A.; Saritaş, T.B.; Görücü, F.; Becit, N. Does Anzer Propolis Have a Protective Effect on Rabbit Spinal Cord Ischemia/Reperfusion Injury? Braz. J. Cardiovasc. Surg. 2021. [CrossRef]

15. Bazmandegan, G.; Shamsizadeh, A.; FathiNajafi, M.; Assadollahi, Z.; Allahtavakoli, M.; Kamiab, Z.; Vakilian, A.; MoghadamAhmadi, A.; Amirteimoury, M.; Boroushaki, M.T. Iranian brown propolis possesses neuroprotective effect against ischemic neuronal damage in mice. J. Herbmed Pharmacol. 2020, 9, 121-129. [CrossRef]

16. Tandean, S.; Japardi, I.; Loe, M.L.; Riawan, W.; July, J. Protective effects of propolis extract in a rat model of traumatic brain injury via hsp70 induction. Open Access Maced. J. Med. Sci. 2019, 7, 2763-2766. [CrossRef] [PubMed]

17. Zhan, Z.; Du, H.; Luo, X.-L.; Liu, R.-S.; Huang, L.; Cao, C.-S. Caffeic Acid Phenethyl Ester Inhibits the Progression of Elastase Induced Aortic Aneurysm in Rats. Int. J. Pharmacol. 2019, 15, 385-393. [CrossRef]

18. Bazmandegan, G.; Boroushaki, M.T.; Shamsizadeh, A.; Ayoobi, F.; Hakimizadeh, E.; Allahtavakoli, M. Brown propolis attenuates cerebral ischemia-induced oxidative damage via affecting antioxidant enzyme system in mice. Biomed. Pharmacother. 2017, 85, 503-510. [CrossRef]

19. Gao, L.; Xu, X.; Gao, P.; Sun, L. The Neuroprotective Effects of Propolis and Its Ingredients. J. Chin. Inst. Food Sci. Technol. 2017, 17, 60-66. [CrossRef]

20. Durak, M.A.; Öztanir, M.N.; Başak Türkmen, N.; Çiftçi, O.; Taşlidere, A.; Tecellioğlu, M.; Önder, A. Chrysin prevents brain damage caused by global cerebral ischemia/reperfusion in a C57BL/J6 mouse model. Turk. J. Med. Sci. 2016, 46, $1926-1933$. [CrossRef]

21. Barbosa, R.A.; Nunes, T.L.G.M.; Da Paixão, A.O.; Neto, R.B.; Moura, S.; Albuquerque, R.L.C., Jr.; Cândido, E.A.F.; Padilha, F.F.; Quintans-Júnior, L.J.; Gomes, M.Z.; et al. Hydroalcoholic extract of red propolis promotes functional recovery and axon repair after sciatic nerve injury in rats. Pharm. Biol. 2016, 54, 993-1004. [CrossRef] [PubMed]

22. Yüce, S.; Cemal Gökçe, E.; Işkdemir, A.; Koç, E.R.; Cemil, D.B.; Gökçe, A.; Sargon, M.F. An experimental comparison of the effects of propolis, curcumin, and methylprednisolone on crush injuries of the sciatic nerve. Ann. Plast. Surg. 2015, 74, 684-692. [CrossRef]

23. Brasil, F.B.; de Almeida, F.J.S.; Luckachaki, M.D.; Dall'Oglio, E.L.; de Oliveira, M.R. Pinocembrin pretreatment counteracts the chlorpyrifos-induced HO-1 downregulation, mitochondrial dysfunction, and inflammation in the SH-SY5Y cells. Metab. Brain Dis. 2021, 1-15. [CrossRef] 
24. Ayna, A.; Özbolat, S.N.; Darendelioglu, E. Quercetin, chrysin, caffeic acid and ferulic acid ameliorate cyclophosphamide-induced toxicities in SH-SY5Y cells. Mol. Biol. Rep. 2020, 47, 8535-8543. [CrossRef]

25. Darendelioglu, E. Neuroprotective Effects of Chrysin on Diclofenac-Induced Apoptosis in SH-SY5Y Cells. Neurochem. Res. 2020, 45, 1064-1071. [CrossRef]

26. Omar, N.A.; Abu-Almaaty, A.H.; Abd El-Aziz, Y.M.; Abdeen, A.M.; Mohamed, F.E.Z.A.; Hashem, M.M.M.; Hammad, S. Impacts of Egyptian propolis extract on rat cerebellum intoxicated by aluminum silicate: Histopathological studies. Environ. Sci. Pollut. Res. 2019, 26, 22061-22068. [CrossRef]

27. Hussein, U.K.; Hassan, N.E.-H.Y.; Elhalwagy, M.E.A.; Zaki, A.R.; Abubakr, H.O.; Venkata, K.C.N.; Jang, K.Y.; Bishayee, A. Ginger and propolis exert neuroprotective effects against monosodium glutamate-induced neurotoxicity in rats. Molecules 2017, 22, 1928 [CrossRef] [PubMed]

28. Kassab, A.A.; Elkaliny, H.H. The possible role of propolis in ameliorating paclitaxel-induced peripheral neuropathy in sciatic nerve of adult male albino rats. Egypt. J. Histol. 2017, 40, 141-155. [CrossRef]

29. Mostafa, R.E.; Salama, A.A.A.; Abdel-Rahman, R.F.; Ogaly, H.A. Hepato-and neuro-protective influences of biopropolis on thioacetamide-induced acute hepatic encephalopathy in rats. Can. J. Physiol. Pharmacol. 2017, 95, 539-547. [CrossRef] [PubMed]

30. Khalil, F.A.; EL-Kirsh, A.A.A.; Kamel, E.A.; EL-Rahmany, N.G. Beneficial Effect of Propolis Extract (Bee Glue) against MethotrexateInduced Stress in Liver and Brain of Albino Rats. Indian J. Med. Res. Pharm. Sci. 2016, 3, 24-35. [CrossRef]

31. Taysi, S.; Demir, E.; Cinar, K.; Tarakcioglu, M. The Radioprotective Effects of Propolis and Caffeic Acid Phenethyl Ester on Radiation-Induced Oxidative/nitrosative Stress in Brain Tissue. Free Radic. Biol. Med. 2016, 100, S111. [CrossRef]

32. Thangarajan, S.; Ramachandran, S.; Krishnamurthy, P. Chrysin exerts neuroprotective effects against 3-Nitropropionic acid induced behavioral despair-Mitochondrial dysfunction and striatal apoptosis via upregulating Bcl-2 gene and downregulating Bax-Bad genes in male wistar rats. Biomed. Pharmacother. 2016, 84, 514-525. [CrossRef] [PubMed]

33. Gocmez, S.; Demirtas, T.; Aksoz, E.; Utkan, T.; Gacar, N. P.1.h.009 Protective effects of an extract of propolis in scopolamineinduced cognitive impairment in rats. Eur. Neuropsychopharmacol. 2015, 25, S286. [CrossRef]

34. Alkis, H.E.E.; Kuzhan, A.; Dirier, A.; Tarakcioglu, M.; Demir, E.; Saricicek, E.; Demir, T.; Ahlatci, A.; Demirci, A.; Cinar, K.; et al. Neuroprotective effects of propolis and caffeic acid phenethyl ester (CAPE) on the radiation-injured brain tissue (neuroprotective effects of propolis and CAPE). Int. J. Radiat. Res. 2015, 13, 297-303. [CrossRef]

35. Dos Santos, N.A.G.; Martins, N.M.; de Silva, R.B.; Ferreira, R.S.; Sisti, F.M.; dos Santos, A.C. Caffeic acid phenethyl ester (CAPE) protects PC12 cells from MPP+ toxicity by inducing the expression of neuron-typical proteins. Neurotoxicology 2014, 45, 131-138. [CrossRef]

36. Swamy, M.; Suhaili, D.; Sirajudeen, K.N.S.; Mustapha, Z.; Govindasamy, C. Propolis ameliorates tumor nerosis factor- $\alpha$, nitric oxide levels, caspase-3 and nitric oxide synthase activities in kainic acid mediated excitotoxicity in rat brain. African J. Tradit. Complement. Altern. Med. 2014, 11, 48-53. [CrossRef]

37. Newairy, A.A.; Abdou, H.M. Effect of propolis consumption on hepatotoxicity and brain damage in male rats exposed to chlorpyrifos. African J. Biotechnol. 2013, 12, 5232-5243. [CrossRef]

38. Mahmoud, S.M.; El-Yamany, N.A. The protective effect of propolis on norepinephrine, dopamine and 5-hydroxytryptamine content in thalamus-hypothalamus and cerebellum of endotoxin-intoxicated adult male albino rats. Life Sci. J. 2012, 9, 3372-3379.

39. Ramezani, M.; Hesami, M.D.; Rafiei, Y.; Ghareghozloo, E.R.; Meratan, A.A.; Nikfarjam, N. Efficient Amyloid Fibrillation Inhibition and Remodeling of Preformed Fibrils of Bovine Insulin by Propolis Polyphenols-Based Nanosheets. ACS Appl. Bio Mater. 2021, 4, 3547-3560. [CrossRef]

40. Tamfu, A.N.; Fotsing, M.T.; Talla, E.; Ozturk, M.; Mbafor, J.T.; Duru, M.E.; Shaheen, F. Chemical composition and evaluation of anticholinesterase activity of essential oil from Cameroonian propolis. Issues Biol. Sci. Pharm. Res. 2019, 7, 58-63. [CrossRef]

41. Boulechfar, S.; Zellagui, A.; Chemsa, A.E.; Bensouici, C.; Segueni, N.; Lahouel, M.; Öztürk, M.; Duru, M.E. Investigation of Antioxidant and Anticholinesterase Potential of Essential Oil and Methanolic Extract of Propolis from Mila Region. J. Biol. Act. Prod. Nat. 2019, 9, 434-444. [CrossRef]

42. Nanaware, S.; Shelar, M.; Sinnathambi, A.; Mahadik, K.R.R.; Lohidasan, S. Neuroprotective effect of Indian propolis in $\beta$-amyloid induced memory deficit: Impact on behavioral and biochemical parameters in rats. Biomed. Pharmacother. 2017, 93, 543-553. [CrossRef] [PubMed]

43. Gülçin, I.; Scozzafava, A.; Supuran, C.T.; Akıncıŏlu, H.; Koksal, Z.; Turkan, F.; Alwasel, S. The effect of caffeic acid phenethyl ester (CAPE) on metabolic enzymes including acetylcholinesterase, butyrylcholinesterase, glutathione S-transferase, lactoperoxidase, and carbonic anhydrase isoenzymes I, II, IX, and XII. J. Enzym. Inhib. Med. Chem. 2016, 31, 1095-1101. [CrossRef]

44. Liu, R.; Wu, C.X.; Zhou, D.; Yang, F.; Tian, S.; Zhang, L.L.; Zhang, T.-T.; Du, G.-H. Pinocembrin protects against $\beta$-amyloid-induced toxicity in neurons through inhibiting receptor for advanced glycation end products (RAGE)-independent signaling pathways and regulating mitochondrion-mediated apoptosis. BMC Med. 2012, 10, 1-21. [CrossRef]

45. Ayikobua, E.T.; Kasolo, J.; Kasozi, K.I.; Eze, E.D.; Safiriyu, A.; Ninsiima, H.I.; Kiyimba, K.; Namulema, J.; Jjesero, E.; Ssempijja, F.; et al. Synergistic action of propolis with levodopa in the management of Parkinsonism in Drosophila melanogaster. J. Complement. Integr. Med. 2020, 17. [CrossRef]

46. Gonçalves, V.C.; Pinheiro, D.J.L.L.; de la Rosa, T.; de Almeida, A.C.G.; Scorza, F.A.; Scorza, C.A. Propolis as a potential diseasemodifying strategy in parkinson's disease: Cardioprotective and neuroprotective effects in the 6-ohda rat model. Nutrients 2020, 12, 1551. [CrossRef] 
47. Gomes, M.; Barroso, S.; de Oliveira, J.; Marques, D.; Santos, A.; Cardoso, J. Neuroprotective actions of red propolis extract and formononetin in a rat model of Parkinson's disease. Mov. Disord. 2019, 34, S502.

48. Safari, M.; Sameni, H.R.; Badban, L.; Bandegi, A.R.; Vafaei, A.A.; Pour, A.R.; Ghahari, L. Protective effects of water extract of propolis on dopaminergic neurons, brain derived neurotrophic factor and stress oxidative factors in the rat model of parkinson's disease. Int. J. Pharmacol. 2015, 11, 300-308. [CrossRef]

49. Barros Silva, R.; Santos, N.A.G.; Martins, N.M.; Ferreira, D.A.S.; Barbosa, F., Jr.; Oliveira Souza, V.C.; Kinoshita, Â.; Baffa, O.; Del-Bel, E.; Santos, A.C. Caffeic acid phenethyl ester protects against the dopaminergic neuronal loss induced by 6hydroxydopamine in rats. Neuroscience 2013, 233, 86-94. [CrossRef]

50. Yilmaz, U.C.; Bagca, B.G.; Karaca, E.; Durmaz, A.; Durmaz, B.; Aykut, A.; Kayalar, H.; Avci, C.B.; Susluer, S.Y.; Pariltay, E.; et al. Propolis Extract Regulate microRNA Expression in Glioblastoma and Brain Cancer Stem Cells. Anticancer. Agents Med. Chem. 2021, 21. [CrossRef]

51. Keskin, S.; Çetin, E.A. Lavender Volatile Oil: A New Solvent for Propolis Extraction, Chemical Composition, Antioxidant Activity and Cytotoxicity on T98G Glioblastoma Cell Line. J. Essent. Oil-Bear. Plants 2020, 23, 514-521. [CrossRef]

52. Agca, C.A.; Tykhomyrov, A.A.; Baydas, G.; Nedzvetsky, V.S. Effects of a Propolis Extract on the Viability of and Levels of Cytoskeletal and Regulatory Proteins in Rat Brain Astrocytes: An In Vitro Study. Neurophysiology 2017, 49, 261-271. [CrossRef]

53. Kalia, P.; Kumar, N.R.; Harjai, K. Studies on the effect of ethanolic extract of propolis in BALB/c mice. J. Appl. Nat. Sci. 2014, 6, 638-643. [CrossRef]

54. Markiewicz-Zukowska, R.; Car, H.; Naliwajko, S.K.; Sawicka, D.; Szynaka, B.; Chyczewski, L.; Isidorov, V.; Borawska, M.H. Ethanolic extract of propolis, chrysin, CAPE inhibit human astroglia cells. Adv. Med. Sci. 2012, 57, 208-216. [CrossRef] [PubMed]

55. Asama, T.; Hiraoka, T.; Ohkuma, A.; Okumura, N.; Yamaki, A.; Urakami, K. Cognitive Improvement and Safety Assessment of a Dietary Supplement Containing Propolis Extract in Elderly Japanese: A Placebo-Controlled, Randomized, Parallel-Group, Double-Blind Human Clinical Study. Evid.-Based Complement. Altern. Med. 2021, 2021, 6664217. [CrossRef] [PubMed]

56. Gocmez, S.S.; Celebi, G.; Demirtaş-Şahin, T.; Aksoz, E.; Utkan, T.P. 480 The effects of propolis extract on age-associated cognitive deficits in rats. Eur. Neuropsychopharmacol. 2019, 29, S337-S338. [CrossRef]

57. Liu, Y.; Wu, Z.; Zhu, A.; Nakanishi, H.; Ni, J.; Zhong, X.; Meng, J.; Wu, S. Brazilian green propolis improves cognitive functions and modulates systemic cytokines in elderly people living at high altitude. J. Neurol. Sci. 2017, 381, 678-679. [CrossRef]

58. Li, Y.L.; Zhong, X.; Du, C.; Li, H.J.; Wu, Z.; Nakanishi, H.; Zhu, A.Q. Clinical significance of brazilian propolis interference in patients with mild cognitive impairment (MCI) in plateau area of serum c-reactive protein (HS-CRP) and lipid metabolism disorders. J. Am. Geriatr. Soc. 2014, 62, S361.

59. Nosratiyan, M.; Farjah, G.H.; Karimipour, M.; Pourheidar, B. The Effect of Propolis-Gum Arabic as a Novel Nerve Guidance Channel on Regeneration of Sciatic Nerve in Male Rats. Turk. Neurosurg. 2021, 31, 361-367. [CrossRef]

60. Shao, Q.; Zhao, M.; Pei, W.; Pu, Y.; Liu, M.; Liu, W.; Yu, Z.; Chen, K.; Liu, H.; Deng, B.; et al. Pinocembrin Promotes OPC Differentiation and Remyelination via the mTOR Signaling Pathway. Neurosci. Bull. 2021, 37, 1314-1324. [CrossRef]

61. Li, Z.; Chu, S.; He, W.; Zhang, Z.; Liu, J.; Cui, L.; Yan, X.X.; Li, D.; Chen, N. A20 as a novel target for the anti-neuroinflammatory effect of chrysin via inhibition of NF-kB signaling pathway. Brain. Behav. Immun. 2019, 79, 228-235. [CrossRef]

62. Kuswati, K.; Handayani, E.S.; Nugraha, Z.S.; Rahmanti, F.A.; Wicaksana, Z.L.; Zhafirrahman, M. Propolis inhibited Bax expression and increased neuronal count of hippocampal area CA1 in rats receiving sodium nitrite. Universa Med. 2019, 38, 73-78. [CrossRef]

63. Lee, B.K.; Lee, W.J.; Jung, Y.-S. Chrysin attenuates VCAM-1 expression and monocyte adhesion in lipopolysaccharide-stimulated brain endothelial cells by preventing NF-kB signaling. Int. J. Mol. Sci. 2017, 18, 1424. [CrossRef]

64. Wu, Z.; Liu, Y.; Zhu, A.; Wu, S.; Nakanishi, H. Brazilian green propolis suppresses microglia-mediated neuroinflammation by inhibiting NF-kB activation. J. Neurol. Sci. 2017, 381, 678. [CrossRef]

65. Cavendish, R.L.; Santos, J.d.S.; Neto, R.B.; Paixão, A.O.; Oliveira, J.V.; Araujo, E.D.D.; Silva, A.A.B.; Thomazzi, S.M.; Cardoso, J.C.; Gomes, M.Z. Antinociceptive and anti-inflammatory effects of Brazilian red propolis extract and formononetin in rodents. J. Ethnopharmacol. 2015, 173, 127-133. [CrossRef] [PubMed]

66. Mountassir, M.; Chaib, S.; Selami, Y.; Khalki, H.; Ouachrif, A.; Moubtakir, S.; Aboufatima, R.; Zyad, A.; Benharref, A.; Chait, A. Antinociceptive Activity and Acute Toxicity of Moroccan Black Propolis. Int. J. Eng. Res. Technol. 2014, 3, $2393-2397$.

67. Wu, Z.; Zhu, A.; Takayama, F.; Okada, R.; Liu, Y.; Harada, Y.; Wu, S.; Nakanishi, H. Brazilian green propolis suppresses the hypoxia-induced neuroinflammatory responses by inhibiting NF-B activation in microglia. Oxid. Med. Cell. Longev. 2013, 2013, 906726. [CrossRef] [PubMed]

68. Franchin, M.; Da Cunha, M.G.; Denny, C.; Napimoga, M.H.; Cunha, T.M.; Koo, H.; de Alencar, S.M.; Ikegaki, M.; Rosalen, P.L. Geopropolis from Melipona scutellaris decreases the mechanical inflammatory hypernociception by inhibiting the production of IL-1 $\beta$ and TNF- $\alpha$. J. Ethnopharmacol. 2012, 143, 709-715. [CrossRef]

69. Kaya, G.B.; Emre, M.H. Effects of Propolis on Spatial Memory Induced by Lithium Pilocarpine in the Experimental Status Epilepticus Model in the Rats. J. Nat. Sci. Res. 2019, 215, 19. [CrossRef]

70. Yiş, U.; Topçu, Y.; Özbal, S.; Tuğyan, K.; Bayram, E.; Karakaya, P.; Yilmaz, O.; Kurul, S.H. Caffeic acid phenethyl ester prevents apoptotic cell death in the developing rat brain after pentylenetetrazole-induced status epilepticus. Epilepsy Behav. 2013, 29, 275-280. [CrossRef] 
71. Gocmez, S.S.; Ozer, C.; Celebi, G.; Yazir, Y.; Duruksu, G.; Demirtaş-Şahin, T.; Uckan, F.; Utkan, T.P. 217 The effects of propolis on cognitive impairment in chronic unpredictable mild stress-induced depression model of rats. Eur. Neuropsychopharmacol. 2019, 29, S167-S168. [CrossRef]

72. Nugroho, K.; Handayani, E.S.; Nugraha, Z.S. Propolis increases neuronal count in hippocampal area CA1 and prefrontal cortex in stressed rats. Universa Med. 2017, 36, 214-220. [CrossRef]

73. Filho, C.B.; Jesse, C.R.; Donato, F.; Del Fabbro, L.; de Gomes, M.G.; Goes, A.T.R.; Souza, L.C.; Giacomeli, R.; Antunes, M.; Luchese, C.; et al. Neurochemical factors associated with the antidepressant-like effect of flavonoid chrysin in chronically stressed mice. Eur. J. Pharmacol. 2016, 791, 284-296. [CrossRef] [PubMed]

74. Filho, C.B.; Jesse, C.R.; Donato, F.; Del Fabbro, L.; Gomes, M.G.D.; Goes, A.T.R.; Souza, L.C.; Boeira, S.P. Chrysin promotes attenuation of depressive-like behavior and hippocampal dysfunction resulting from olfactory bulbectomy in mice. Chem. Biol. Interact. 2016, 260, 154-162. [CrossRef]

75. Lee, M.S.; Kim, Y.H.; Lee, B.R.; Kwon, S.H.; Moon, W.J.; Hong, K.S.; Song, Y.S.; Morita, K.; Hahm, D.H.; Shim, I.; et al. Novel antidepressant-like activity of caffeic acid phenethyl ester is mediated by enhanced glucocorticoid receptor function in the hippocampus. Evid.-Based Complement. Altern. Med. 2014, 2014, 646039. [CrossRef] [PubMed]

76. Lee, M.S.; Kim, Y.H.; Park, W.S.; Ahn, W.G.; Park, O.K.; Kwon, S.H.; Morita, K.; Shim, I.; Her, S. Novel antidepressant-like activity of propolis extract mediated by enhanced glucocorticoid receptor function in the hippocampus. Evid.-Based Complement. Altern. Med. 2013, 2013, 217853. [CrossRef] [PubMed]

77. Ozcan, H.; Ulkevan, T. Propolis induced mania with psychotic features: A case report. Klin. Psikofarmakol. Bul. 2015, 25, 207-208. [CrossRef]

78. Yang, Z.H.; Sun, X.; Qi, Y.; Mei, C.; Sun, X.B.; Du, G.H. Uptake characteristics of pinocembrin and its effect on p-glycoprotein at the blood-brain barrier in in vitro cell experiments. J. Asian Nat. Prod. Res. 2012, 14, 14-21. [CrossRef] [PubMed]

79. Gonçalves, A.C.; Rodrigues, M.; Santos, A.O.; Alves, G.; Silva, L.R. Antioxidant status, antidiabetic properties and effects on Caco-2 cells of colored and non-colored enriched extracts of sweet cherry fruits. Nutrients 2018, 10, 1688. [CrossRef]

80. Silveira, M.; Teles, F.; Melo, E.; Borges, V.; Miranda, F.; Dutra, F.; Berretta, A.; Cezar, R.; Silva, J.; Santos, H.; et al. P1574Effects of Brazilian Green Propolis Extract (Epp-Af) on Inflammation in Hemodialysis Patients. Nephrol. Dial. Transpl. 2020, 35 (Suppl. 3), gfaa142.P1574. [CrossRef]

81. Hesami, S.; Hashemipour, S.; Shiri-Shahsavar, M.R.; Koushan, Y.; Haghighian, H.K. Administration of Iranian Propolis attenuates oxidative stress and blood glucose in type II diabetic patients: A randomized, double-blind, placebo-controlled, clinical trial. Casp. J. Intern. Med. 2019, 10, 48-54. [CrossRef]

82. El-Sharkawy, H.M.; Anees, M.M.; Van Dyke, T.E. Propolis Improves Periodontal Status and Glycemic Control in Patients with Type 2 Diabetes Mellitus and Chronic Periodontitis: A Randomized Clinical Trial. J. Periodontol. 2016, 87, 1418-1426. [CrossRef] [PubMed]

83. Shang, H.; Bhagavathula, A.S.; Aldhaleei, W.A.; Rahmani, J.; Karam, G.; Rinaldi, G.; Clark, C.; Salehisahlabadi, A.; Yuan, Q. Effect of propolis supplementation on C-reactive protein levels and other inflammatory factors: A systematic review and meta-analysis of randomized controlled trials. J. King Saud Univ.-Sci. 2020, 32, 1694-1701. [CrossRef]

84. Zulhendri, F.; Felitti, R.; Fearnley, J.; Ravalia, M. The Use of Propolis in Dentistry, Oral Health, and Medicine: A Review. J. Oral Biosci. 2021. [CrossRef] [PubMed]

85. Šuran, J.; Cepanec, I.; Mašek, T.; Starčević, K.; Gajger, I.T.; Vranješ, M.; Radić, B.; Radić, S.; Kosalec, I.; Vlainić, J. Nonaqueous polyethylene glycol as a safer alternative to ethanolic propolis extracts with comparable antioxidant and antimicrobial activity. Antioxidants 2021, 10, 978. [CrossRef] [PubMed]

86. Šuran, J.; Cepanec, I.; Mašek, T.; Radić, B.; Radić, S.; Tlak Gajger, I.; Vlainić, J. Propolis Extract and Its Bioactive Compounds-From Traditional to Modern Extraction Technologies. Molecules 2021, 26, 2930. [CrossRef]

87. Grozdanova, T.; Trusheva, B.; Alipieva, K.; Popova, M.; Dimitrova, L.; Najdenski, H.; Zaharieva, M.M.; Ilieva, Y.; Vasileva, B.; Miloshev, G.; et al. Extracts of medicinal plants with natural deep eutectic solvents: Enhanced antimicrobial activity and low genotoxicity. BMC Chem. 2020, 14, 73. [CrossRef] 